Portland State University

PDXScholar

1983

\title{
The work values of secondary teachers : a comparative study by teaching assignment
}

Charlotte Marie Klampe

Portland State University

Follow this and additional works at: https://pdxscholar.library.pdx.edu/open_access_etds

Part of the Health and Physical Education Commons, and the Psychology Commons Let us know how access to this document benefits you.

\section{Recommended Citation}

Klampe, Charlotte Marie, "The work values of secondary teachers : a comparative study by teaching assignment" (1983). Dissertations and Theses. Paper 3271.

https://doi.org/10.15760/etd.3261

This Thesis is brought to you for free and open access. It has been accepted for inclusion in Dissertations and Theses by an authorized administrator of PDXScholar. Please contact us if we can make this document more accessible: pdxscholar@pdx.edu. 
AN ABSTRACT OF THE THESIS OF Charlotte Marie Klampe for the Master of Science in Education presented May 18, 1983.

Title: The Work Values of Secondary Teachers: A Comparative Study by Teaching Assignment.

APPROVED BY MEMBERS OF THE THESIS COMMITTEE:
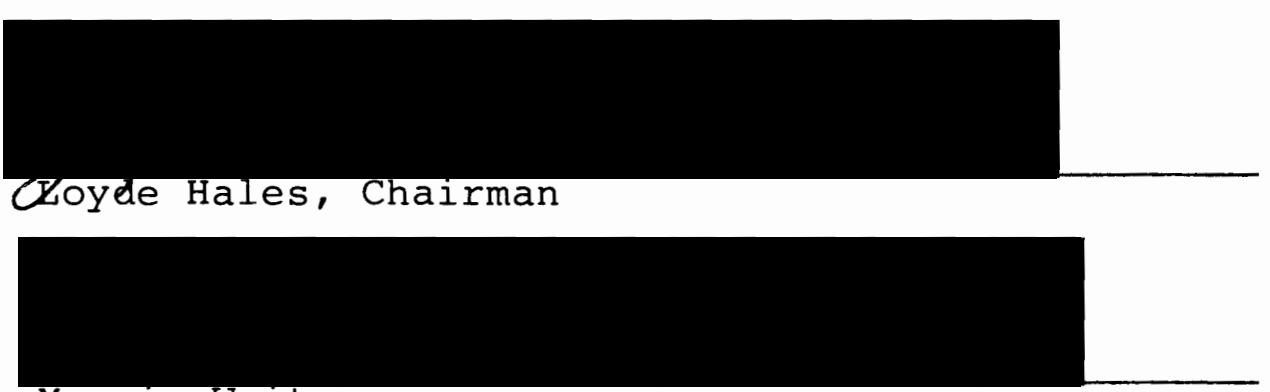

Morris weitman

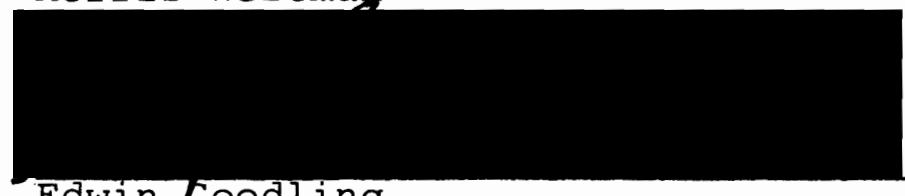

Edwin Foodling

The focus of this study was on the work values of secondary school teachers. Values have been defined in many ways. The common agreement is that values are standards, beliefs, or principles that do guide and direct a person's behavior. The values a teacher holds will influence a student due to the natural role-modeling effect in the classroom. With the advent of career education and exploration of the world of work, the values held toward work become a timely topic. The discussion of values and value 
clarification in all aspects of a person's life is one that is becoming very popular in education.

Teachers from 12 oregon junior and senior high schools, both urban and rural, provided data for this study. The 220 teachers in the sample were from 16 different teaching areas. Biographical information was listed by frequency and percentage. The teachers had a median age of 42.17 and were split $48 \%$ males and $51 \%$ females. The median years of teaching experience was 12.77 years.

The study participants completed the Ohio Work Values Inventory (OWVI) and a biographical data sheet. The means, standard deviations, and medians of the OWVI scales were calculated for the total teacher sample. Frequency and percentages were also listed for each of the 11 OWVI scales.

The range of means for the total sample on the OWVI scales was 16.18 points. The results showed that secondary teachers placed the most value on Task Satisfaction, SelfRealization, and Altruism and the least value on Prestige, Object Orientation, and Solitude.

A multivariate analysis of variance was performed with subject areas as the independent variable and the scales of the OWVI as the dependent variable. The statistical hypothesis was rejected, and univariate analyses of variance were performed on the 11 dependent variables.

Two statistical hypotheses were rejected at the .05 level. Significant differences were found among groups for 
Control and Self-Realization. All pair-wise mean comparisons were performed on these two variables, with one statistical hypothesis rejected in the pair-wise comparisons of means. Math/Computer Science teachers placed lesser value on Self-Realization than did Business teachers.

Scale means were listed by sex of the teacher. A multivariate analysis of variance was performed with sex as the independent variable and the OWVI scales as the dependent variable. The statistical hypothesis was rejected, and univariate analyses of variance were performed on the 11 dependent variables, with four being rejected at the .05 level. Significant differences were found; female teachers placed more value on Self-Realization. Males placed significantly higher value on Solitude, Prestige, and object Orientation than did the female teachers. 
THE WORK VALUES OF SECONDARY'TEACHERS: A COMPARATIVE STUDY BY TEACHING ASSIGNMENT

by

CHARLOTTE MARIE KLAMPE

A thesis submitted in partial fulfillment of the requirements for the degree of

MASTER OF SCIENCE

in

EDUCATION

Portland State University

1983 
TO THE OFFICE OF GRADUATE STUDIES AND RESEARCH:

The members of the Committee approve the thesis of Charlotte Marie Klampe presented May 18, 1983.

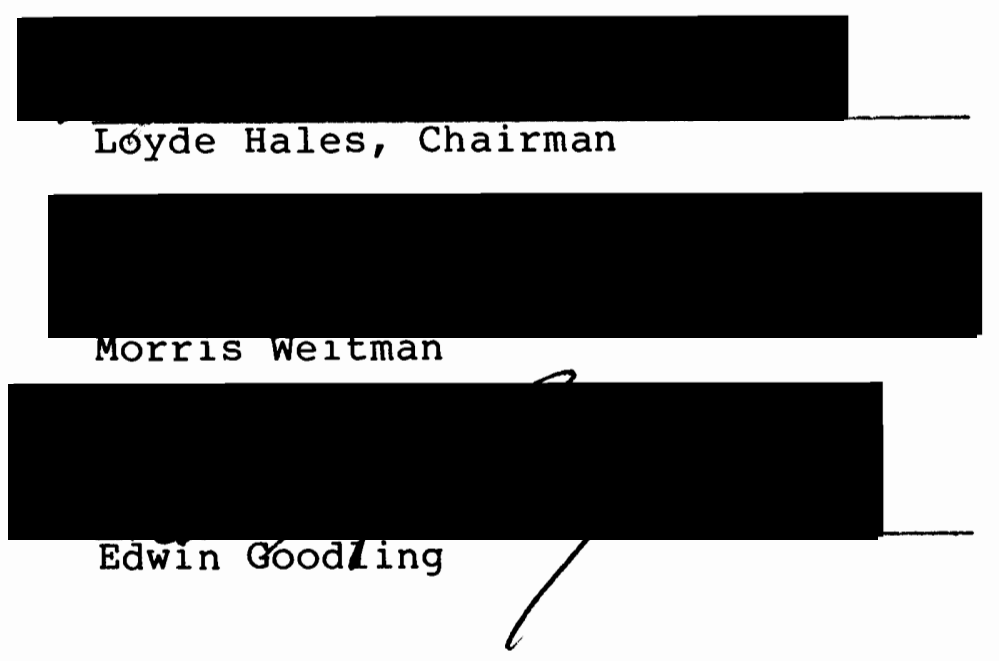

APPROVED :

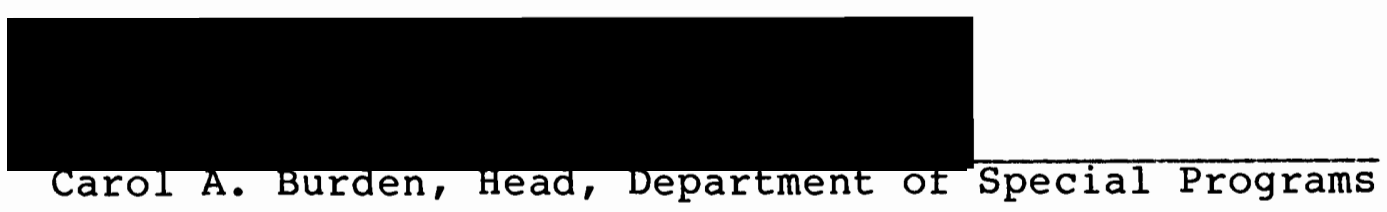

S. E. Rauch y Dean of Graduate studies and Research 


\section{ACKNOWLEDGEMENTS}

Acknowledgement is due to all faculty members at portland State University who have stimulated and guided my interest in this study, and in general course work throughout the last year. I am grateful to Dr. Morris Weitman and Dr. Edwin Goodling for their interest and assistance in the progress and completion of this research project, and for serving on my thesis committee.

Particular appreciation is given to Dr. Loyde Hales, advisor and chairman of my committee. His intellectual abilities and design expertise contributed greatly to this work. His assistance in organizing and analyzing the data was invaluable.

Appreciation is expressed to all the members of my family who helped in scoring and compiling data. I thank my husband, Norman, and my parents, Margaret and Eldon Crabtree, for their support and encouragement during this project. I thank my children, John and Gretchen, for their understanding and patience.

Deepest appreciation goes to two people who did, during their lives, and even today, continue to afford great influence in my life. To my Grandmother, Esther, a thank you for being so supportive of my educational aspirations, and for always being my biggest cheerleader, I know you 
would be very proud. Also, to my dear friend Pat, who taught me more than he will ever know. His constant friendship and unquestioning love made me a better person. 
Dedicated to:

the loving memory of

Esther Johanna Gragg

and

Patrick Steven Carmichael 
TABLE OF CONTENTS

PAGE

ACKNOWLEDGEMENTS

ii

LIST OF TABLES

CHAPTER

I INTRODUCTION . . . . . . . . . . . 1

Introduction to the Problem . . . . . 1

Statement of the Problem....... 5

Impetus for the Study . . . . . . 5

Purpose of the Study . . . . . . . 6

Limitations . . . . . . . . . 7

Delimitations . . . . . . . . . 7

Definition of Terms . . . . . . 8

Outline of Chapters . . . . . . . . 11

I I REVIEW OF RELATED LITERATURE . . . . . . 12

An Introduction to Values .. . . . . 12

Values Clarification and Education . . . 14

Characteristics of Human Values . . . 16

Work Values of Other Groups . . . . 18

Teachers and Work Values . . . . . . 24

The Teacher as a Value Builder . . . . 29

The Teacher as a Role Model . . . . 31 
III METHODOLOGY • • . • • • • • • • •

Design of the Study . . . . . . . 35 Subjects............ 35

Instrumentation ........ . 36

Biographical Data Sheet

ohio work Values Inventory

Procedures . . . . . . . . . . 41

Statistical Methods ......... . 43

IV PRESENTATION OF THE DATA . . . . . . . 45

Description of the Sample ..... . 45

Principal Findings . . . . . . . 51

Descriptive Data: Total Teacher Sample

Data: By Subject Area

Data: by Sex of the Teacher

V ANALYSIS OF DATA • . . . . . . . . . 73

Summary of the Study . . . . . . . 73

Conclusions . . . . . . . . . 75

Recommendations for Further Research . . 77

A SELECTED BIBLIOGRAPHY . . . . . . . . . . . 79

APPENDIX . . . . . . . . . . . . . . 85

A OHIO WORK VALUES INVENTORY . . . . . . 85

B BIOGRAPHICAL DATA SHEET . . . . . . 86

C COVER LETTER TO STUDY PARTICIPANTS . . • . 87

D OWVI SCALE-SCORE PERCENTAGES . . . . . . 89

E SCHOOLS PARTICIPATING IN THE STUDY . . . 113 


\section{LIST OF TABLES}

TABLE

PAGE

I Selected Biographical Characteristics of the Sample by School Location . . . . .

II Selected Biographical Characteristics of the Sample by Teaching Area . . . . . .

III Selected Biographical Characteristics of the Sample by Sex . . . . . . . . .

IV Selected Biographical Characteristics of the Sample by Age . . . . . . . . . .

V Selected Biographical Characteristics of the Sample by Teaching Experience . . . .

VI Scale Means and Standard Deviations of Total Sample... . . . . . . . 52

VII Teacher Scale Scores for Altruism . . . . . 54 VIII Teacher Scale Scores for Object

Orientation . . . . . . . . . . 55

IX Teacher Scale Scores for Security . . . . . 56

X Teacher Scale Scores for Control . . . . . 57

XI Teacher Scale Scores for Self-Realization . . 58

XII Teacher Scale Scores for Independence . . . 59

XIII Teacher Scale Scores for Money . . . . . . 60

XIV Teacher Scale Scores for Task Satisfaction . . 61

XV Teacher Scale Scores for Solitude . . . . . 62 
TABLE

PAGE

XVI Teacher Scale Scores for Ideas/Data . . . .

XVII Teacher Scale Scores for Prestige . . . . . . 64

XVIII OWVI Scale-Score Means by Subject Area . • • $\quad 65$

XIX OWVI Scale-Score Rankings by Subject Area • . 66

XX OWVI Scale-Score Analysis of Variance by

Teaching Area . . . . . . . . . . 69

XXI OWVI Scale-Score Means by Sex of

the Teacher . . . . . . . . . . . . 70

XXII OWVI Scale-Score Analysis of Variance by

Sex of the Teacher . . . . . . . . . •

72 
CHAPTER I

INTRODUCTION

Introduction to the Problem

In recent years the trend toward the study of values, attitudes, and value clarification has become a topic in a variety of disciplines. In the field of education, the focus on values is not only evident in curriculum planning, goals, and objectives, but also in the more personal realm of focus on the values educators should, or do, teach in the classroom.

With the increased popularity of defining educational objectives according to Bloom's taxonomy of cognitive and affective domains, both the "intellectual" and the "feeling or emotional" parts of learning are desired. Attempts to measure learning or behavior on both scales is the current trend.

On the highest level on the affective scale, Bloom, Krathwohl, and Masia (1974, p. 184) describe the behavior of characterization by a value or value complex.

The generalized set is that which gives an internal consistency to the system of attitudes and values at any particular moment . . . It is sometimes spoken of as a determining tendency, an orientation toward phenomena, or a predisposition to act in a certain way . . . It is a persistent and consistent response to a family of related situations or 
objects. It may often be an unconscious set which guides action without conscious forethought . $\cdot$ it is a basic orientation which enables the individual to reduce and order the complex world about him and to act consistently and effectively in it . . the objectives are so encompassing that they tend to characterize the individual almost completely.

What a person values in life determines greatly his/ her behavioral pattern and interactions with others. Values and the role they play in the world of work (work values) are perceived as being the highest and most permanent. Interests and attitudes, although important, are less influential, and fall lower on the taxonomy according to Bloom et al. (1974). Katz (1963) and Perrone (1965) stressed the importance of a consideration of values in career planning. Several researchers have developed instruments with which to measure work values. Included are: Occupational Rating Scale (Hammond, 1956), Vocational Values Inventory (Stefflre, 1962), Work Values Inventory (Super, 1968), and Ohio Work Values Inventory (Hales \& Fenner, 1973a). The latter is the most recent and has been subjected to a number of subsequent studies.

When discussing the theoretical foundation of the ohio Work Values Inventory (OWVI), Fenner and Hales (1973a, pp. 1-2) state the following:

The theoretical foundations of the instrument, along with much of its basic rationale, can be traced to five primary sources: an analysis of the values used in previous investigations; the personalityneed theory, as postulated by Maslow (1954) and adapted to a theory of occupational choice by 
by Roe (1956), self theory, as postulated by Combs and snygg (1959); and worker-functions, as identified by the United States Department of Labor.

On the basis of these considerations, the authors identified 11 work values and the capability of the instrument to measure them was substantiated by a factor analysis (Fenner \& Hales, 1973a). Other studies measuring work values using the OWVI are cited in subsequent chapters of this text.

As described by Hales and Fenner (1972a) and Gribbon and Lohnes (1965), the values related to the world of work begin to form in early childhood and these values enter into pre-adolescent vocational behavior, continuing to exert an influence in adult life. The existence of values as a part of personality was recognized by Holland (1973) when he determined that a personality type is created by "an increasing differentiation of preferred activities, interests, competencies and values" (p. 12).

This research examines the work values held by secondary teachers. All people have their own personal set of values relating to a variety of aspects in their lives. Because the world of work has become such an important part of the educational system, with the advent of career education and vocational awareness programs, the influence of the teacher in this area is evident. Hales (1977) reported the following: 
School professionals are increasingly being asked to take a part in helping young people become more aware of their value orientations, the process by which values are shaped, and the integration of these into their consideration of work plans. Studies of the world of work and career planning are rapidly becoming an integral part of elementary and middle school curricula. Children are being encouraged to develop an awareness of their value orientations, to understand the processes by which work values are shaped, and to integrate their work values in career planning. (p. l)

Sarason (1973) speaks of the effect of role models on a child. The author suggests that children do not just naturally conform to standards set for them. They frequently take on as their own the standards, values, and attitudes of the persons with whom they identify. Children do not indiscriminately imitate all responses made by all potential models; they will pick and choose. The author points to an example of the relationship between model and observer.

The relationship between the model and the observer (which it may not be possible to describe entirely in terms of observable events) can influence the observer's thinking processes as well as his overt behavior. For example, it may be necessary that the acquisition of skills for novel and creative thinking be preceded by acquisition of the ability to explore unlikely paths to solutions. The teacher who provides students with examples of this form of adventurousness may help them develop that unique orientation often necessary for creative thought. (p. Il)

Every teacher is a value builder, whether or not he wants to be or recognizes this fact. He has no choice about it. . teaching behavior does contribute to the kinds of need concepts students form; the need concepts are the roots of values. (Tyson \& Carroll, 1970, p. 262) 
If the teacher is to assume this responsibility of value builder and clarifier for students, it is also important for the teacher to have a clearly defined personal value system. Along with this, the teachers must be receptive and open to a variety of value systems that may not match or agree with their own. When speaking of effective teachers, Garrett (1971, p. 26) proposed "that we need independent, facilitating, and non-rigid teachers who are open to experiences, including experiences for others and experiences for themselves."

\section{Statement of the Problem}

The following question provides the principal focus of this study: what are the work values of secondary school teachers? Secondly, do the values towards work held by teachers differ by subject area?

\section{Impetus for the Study}

The observation and study of individual differences have been of interest to the author for some time. As a Home Economist with specialization in Child Development and from many years as a secondary classroom teacher, it has been interesting to observe human characteristics and traits.

The informal groupings and alliances within faculty groups are evident by simple observation. It has been 
observed by the author that these cliques are often formed by subject area taught. These friendships not only seem to thrive within the professional relationship, but also carry over to informal and social interactions as well. It is very common to see the P.E. teachers or coaches sit together, the history teachers group together, etc., whether it be in the lunchroom, faculty meetings, or committee assignments.

Since alliances of any kind need some type of common bond to continue, the study of common values among subject areas is an interesting one to pursue. Narrowing down the values to those relating to the world of work is a logical one, because the study participants have similar roles in the field of education.

\section{Purpose of the study}

The purpose of this study was to determine the general work values held by classroom teachers. The data obtained was subjected to further examination to determine differences which may exist among teachers with different teaching assignments.

Information gained in this type of study can be used in a variety of ways. One benefit could be in evaluating and planning curriculum. It could also help administrators understand and work more effectively with their staff. The results of this study could be used to help teachers 
understand areas of common agreement or the differences among peers in the same or other disciplines. When teachers are more aware of their own personal work values, they can make a conscious effort not to impose their own values on the student in their classrooms.

\section{Limitations}

An attempt was made to seek out teachers in all subject areas, but the resulting sample contained proportionately larger numbers in some fields of teaching. Although this may weaken the reliability of scores within these smaller groups, the obtained distribution of teachers by subject areas is somewhat typical of the makeup in a secondary school staff.

\section{Delimitations}

The delimitations of this study reflect the possible generalizations based upon the specific sample selected, and the particular theory and definitions used by Hales and Fenner.

The population sampled, secondary school teachers, also delimited the study. In generalizing this study's results, one should take into account the characteristics of the population sampled.

Hales and Fenner's 11 work values delimited the scope of the study. The 11 work values as described by Hales and 
Fenner should not be interpreted as an exhaustive list of work values, nor should they be viewed as identical to the work values defined.

\section{Definition of Terms}

The following terms are defined to enable readers to interpret general words which have been given specific, special meaning by Hales and Fenner (1973a). Additional terms have been defined because of their relevance to the study. Altruism scale--Signifies the importance given to the opportunity for involvement with other people in a helping, supportive, or service role. A quality of interpersonal giving by the valuer characterizes the relationships which are developed in the work (Hales \& Fenner, 1973a, p. 9).

Control scale--Indicates the importance of having an opportunity to take a leadership role or responsibility for other workers in the conduct of their work. The job itself gives the person an influencing or decision-making role with regard to the planning, supervision, and evaluation of workers (Hales \& Fenner, 1973a, p. 9).

Ideas/Data scale--Indicates the importance of having an opportunity to work with facts and ideas. A high score on this scale signifies a preference for dealing with, making sense out of, creating, and communicating ideas (Hales \& Fenner, 1973a, p. 10). 
Independence scale--Signifies the importance of work which allows the person to determine his own working conditions. A high scorer on this scale prefers to be free from close supervision and to structure his own hours and methods of working. An element of control--the desire for mastery over the work environment--is expressed in this value. Thus, the scale may be related to the Control scale which reflects a managerial factor regarding people (Hales \& Fenner, 1973a, p. 9).

Money scale--Indicates the importance of work which enables the person to have a substantial income--more than enough to assure basic needs. The value reflects a materialistic outlook--one in which the person's desires for material satisfactions and the psychological gratifications attendant upon wealth can be realized (Hales \& Fenner, $1973 a$, p. 9).

object Orientation--Expresses the valuation of handling, tending, or manipulating physical objects such as utensils, materials, tools, or apparatus. The value related to work which involves making, fixing, operating, or changing the appearance of things, the results of which tend to be readily apparent and measurable (Hales \& Fenner, $1973 a$, p. 9).

Prestige scale--Concerns the desire for work which will bring a person recognition and acclaim. An aspect of 
this value is the opportunity to meet or associate with important people (Hales \& Fenner, 1973a, p. 10).

Secondary teachers--Includes all teachers assigned and certified to teach seventh grade through twelfth grade. Security scale--Concerns the desire for work which is steady and dependable. The work may be full-time, parttime, or seasonal but it is quite immune to unpredictable layoff or dismissal. Since a guarantee of income is reflected in high valuation of security, the value tends to be related to other rewards-of-work values, money, and prestige (Hales \& Fenner, 1973a, p. 9).

Self-Realization--Expresses a preference toward work which permits the individual to utilize his skills, abilities, or talents. The work affords opportunities and challenges for continued personal growth and realization of one's full potential (Hales \& Fenner, 1973a, p. 9).

Solitude scale--Relates the preference for work situations characterized by the absence of close relationships with other people. The work can be done largely by one person and it usually affords either few or brief structured personal encounters (Hales \& Fenner, 1973a, p. 10).

Subject area--Refers to the specific area a teacher is certified to teach. If a teacher is certified in more than one area, the subjects were classified in the area that occupies over $50 \%$ of their instructional time. 
Task Satisfaction scale--Concerns the importance associated with work that generally is interesting and enjoyable. The work tasks are the kinds that an individual can, for the most part, look forward to doing (Hales \& Fenner, 1973a, p. 10).

\section{Outline of Chapters}

Chapter I presented a rationale for the study, statement of problem, purpose, limitations, delimitations, and definition of terms. Chapter II contains the review of related literature. Chapter III describes the methodology of the study. This includes design, subjects, instrumentation, procedures, and statistical methods. Chapter IV includes the presentation of the data, description of the sample, and principal findings. Chapter $\mathrm{V}$ concludes this paper with a summary of the study, conclusions, and recommendations for further research. 
CHAPTER II

\section{REVIEW OF RELATED LITERATURE}

Literature to be reviewed includes a brief overview of the study of values and value clarification in preparation for a more extensive discussion of the research relating to work values. Included also is a discussion of the teacher's role as a value builder and role model.

\section{An Introduction to Values}

It has become fashionable in recent years to speak of the school's "hidden curriculum"--school experiences that result in unintended, unplanned, even unsuspected and undesired student learning. The "hidden" curriculum is typically contrasted with the "formal" curriculum--the experiences purposely planned to accomplish the intended, although often not explicitly stated, goals and objectives of the various curriculum areas. The hidden curriculum includes the unintended implications of content and of teaching behavior, as well as the many noninstructional encounters that students have with teachers and other school personnel. Much of the hidden curriculum has to do with values, even in subjects that are frequently considered "value free"--such as science and mathematics. 
Before proceeding further an operational definition of values is needed. Several authors have given their own definition to the concept of values. Oliver and Shaver (1966); Shaver and Berlack (1968); Shaver and Larkins (1969) would generally agree on the following definition:

Values are our standards and principles for judging work. They are the criteria by which we judge 'things' (people, objects, ideas, actions and situations) to be good, worthwhile, desirable; or on the other hand, bad, worthless despicable; or, of course, somewhere in between these extremes. We apply our values consciously. Or they may function unconsciously, as part of the influence of our frames of reference, without our being aware of the standards implied by our decisions. (Oliver \& Shaver, 1974, p. 15)

Rokeach (1973) describes a value as:

- . an enduring belief that a specific mode of conduct or end-state of existence is personally or socially preferable to an opposite or converse mode of conduct or end-state of existence . . . it is a 'standard' that guides and determines action, attitudes toward objects and situations, ideology, presentations of self to others, evaluations, judgments, justifications, comparisons of self with others, and attempts to influence others. (pp. 5, 25)

Present in both of these definitions, and others, is agreement on the great influence that values hold in our personal and professional lives. The values held by a person will guide his/her behavior, interactions with others, and in all areas of life.

Values held by people encompass many parts of their lives. Values can be determined and examined in such areas as: values held toward family and friends, moral values, 
religious or spiritual values, social values, educational values, and (as examined in this paper) values related to work.

Another important distinction should be made between values and value judgements. Value judgements are assertions we make based on our values (Shaver \& Strong, 1976). A similar yet important distinction can be made between the closely related topics of values and attitudes. An attitude, as commonly defined by psychologists, is a number of interrelated beliefs and feelings focused on some object, individual action, person, situation, or thing. Attitudes are affected by a multitude of factors, including factual beliefs people hold and their values. The term "values" denotes a standard of worth and is a more fundamental frame of reference (Shaver \& Strong, 1976).

\section{Values Clarification and Education}

Louis Raths first used the term "values clarification" in the late fifties. Based on John Dewey's (1939) book, Theory of Valuation, Raths refined Dewey's ideas and created values clarification strategies based on the recorded thoughts of the great philosopher. Raths also was interested in the emotional needs of human beings. According to Simon and de Sherbinin (1975), Raths' works in this area "went even further than that of Abraham Maslow." Purpel and Ryan (1976) state that the concept of values and value 
clarification has become extremely popular since the original Raths book. There are growing numbers of books available to educators that try to teach them to become value clarifiers for their students. Teachers widely report that "values clarification works, they feel that it turns kids on in what is otherwise largely irrelevant curriculum" (Purpel \& Ryan, 1976).

On reporting the benefits of value clarification in the classroom Raths, Harmin, and Simon (1978) list the following:

--An increase in self-direction and trust in oneself (including more self-acceptance). . .

--A maturation of expressed values. . .

- An improvement in the learning climate (more participation, more responsibility for what happens, more interest in learning). . .

- An improvement in learning outcomes (especially in reading). . . .

--A venting of personal pressures (expressing fears and problems). . .

- An increase in hope and faith (more confidence that problems can be solved, progress is possible, personal power can be marshaled). . .

- An improvement in student-teacher relations (more feeling on the part of students that teachers are helpful and kind; more feeling on the part of teachers that students are worthy of respect and affection)... ( .249$)$

The author points out that this approach may not be as effective in all classrooms and with all teachers, but that the majority of teachers find that getting students and themselves closer to their values, greatly helps the curriculum and other factors in the classroom. 
Characteristics of Human Values

The noted psychologist, Rogers, has written extensively on the importance of and problems relating to values. He sees the world culture changing drastically, and the effect on values and relationships between people as in a great pattern of change. No longer are the values of the past held as sacred. Not only are the youth of today rebelling against parental guidance in some areas of their lives, but the patterns of behavior and attitudes of the general population seem to be in a state of re-evaluation and collapse in others.

Men question whether there are, or can be any universal values. It is often felt that we may have lost, in our modern world, all possibility of any general or cross-cultural basis for values. One natural result of this uncertainty and confusion is that there is an increasing concern about, interest in, and a searching for, a sound or meaningful value approach which can hold its own in today's world. (Rogers, 1973)

The values an adult holds are learned and adopted through life experiences. A child spills milk, the parent tells the child that he is naughty. The child spills again and repeats out loud, "I'm naughty, I spilled my milk." The child is trying to behave in terms of values set by another, in this case to hold the love of a parent. A young man observes that his parents respond much more favorably when he suggests going to medical school instead of being a back-up musician for a rock group. Rogers suggests that because these values are not based on his own valuing, they 
tend to be fixed and rigid, instead of fluid and capable of change to meet new experiences. Rogers stresses the importance of any value system being open and receptive to change for the person to experience the positive evolutionary change of maturation.

Rogers (1973) lists some of the commonly introjected (rigid) values held by adults. These values are often widely discrepant from the evidence supplied by the person's experiences.

Sexual desires and behaviors are mostly bad. The sources of this construct are many--parents, churches, teachers.

Disobedience is bad. Here parents and teachers combine with the military to emphasize this concept. To obey is good. To obey without question is even better.

Making money is the highest good. The sources of this conceived value are too numerous to mention.

Learning an accumulation of scholarly facts is highly desirable.

Browsing and aimless exploratory reading for fun is undesirable. The source of these last two concepts is apt to be in the educational system.

Communism is utterly bad. Here the government is a major source.

To love thy neighbor is the highest good. This concept comes from the church, perhaps from the parents.

Cooperation and teamwork are preferable to acting alone. Here companions are an important source.

Cheating is clever and desirable. The peer group again is the origin. (pp. 80-81)

As is evident from this discussion, the values an adult holds are influenced by many people. The values one adopts may not be based on personal experiences but rather on the interaction with others, and the perceived acceptance 
of these actions by those influential people with whom one interacts.

\section{Work Values of Other Groups}

The values toward work have been documented by several researchers in the field. Super developed his work Values Inventory in 1968, and it has been used to describe and draw comparisons between a variety of groups. Hales and Fenner developed the Ohio Work Values Inventory in 1973. It has also been used in research, classroom use, and for guidance procedures.

Previously discussed in prior chapters are the 11 values associated with the OWVI. Listed below are the values associated with the Work Values Inventory developed by Super (1970).

Intrinsic Factors

Achievement

Altruism

Creativity

Aesthetics

Intellectual Stimulation

Management
Extrinsic Factors

Associates

Economic Returns

Independence

Prestige

Security

Supervisory Relations

Surroundings

Variety

Way of Life

When looking at the work values held by a variety of different groups, a review of recent studies is necessary. Vanderink (1980), using the Super inventory, studied the work values of clerical workers and students in preparation for clerical positions. Thomas (1973) investigated 
the effect of social class, race, and sex on the work values of ninth-grade students in a large metropolitan area. Measures of work values were obtained using Super's Work Values Inventory. Significant differences between black and white students appeared for the variables of Associates, Altruism, Variety, and Intellectual Stimulation. Males and females varied on Creativity and Altruism. Where significant differences appeared between blacks and whites, white students in all cases expressed greater value for each of the work value constructs. In general, black females of low social position scored low on the work value scales (Thomas, 1973).

Super's Work Values Inventory was administered to 391 entering community college freshmen in Massachusetts. Grace (1974) listed the following results: Altruism was shown to be positively related to being female; Economic Return was positively related to being male, especially for those in the business administration program; liberal arts' males tended to be more altruistic and security minded; the secretarial group showed a high value orientation to surroundings, but also rated Economic Returns and Supervisory Relations as important.

Work values have not only been used as a descriptive instrument but also as a predictive device. The next two cited studies point to additional uses for work values research. Even though these studies were predictive in 
nature, the existence of measurable work values for the groups is evident.

Gade and Perterson (1977) studied the correlation between work values and vocational maturity for women and men. They found that general work values could only be used as reliable predictors of vocational maturity for women. Drummond, Pinette, and Smith (1977) used Super's Work Values Inventory as one of three scales to determine the best predictor of reading achievement in a reading course at a community college. Five scales of the inventory contributed $13.2 \%$ of the variance in predicting reading achievement.

Values have been shown to have predictive value in determining human goal direction. Krause (1970) studied the relationship between work values and college majors. A random sample of 180 males, representing Holland's six categories of vocational choice (Realistic, Intellectual, Social, Conventional, Enterprising, and Artistic) were administered a modified version of Super's Work Values Inventory. The six groups varied significantly on nine of the 18 values: social welfare, freedom in work, satisfactory supervision, creativity, variety, material esteem, status, family esteem, and religious esteem. The author suggested that these results seem to indicate that vocational counseling should take these differences of values by college majors into account when planning programs for students. 
An extensive study of necessary work values, habits, and attitudes was conducted in Missouri during the late 1970s, using workers, supervisors, teachers, and students in various classifications. This study used an instrument entitled the Affective Work Competencies Inventory (AWCI). This inventory does not deal with values of work, but competencies relating to the world of work, all in the affective domain. Examples of the fifteen clustered categories are:

1. Ambitious

2. Cooperative/Helpful

3. Adaptable/Resourceful

4. Considerate/Courteous

5. Independent/Initiating

6. Accurate/Quality of Work

7. Careful/Alert/Perceptive

8. Pleasant/Friendly/Cheerful

9. Responsive/Follow Directions

10. Emotionally Stable/Judgemental/Poised

11. Persevering/Patient/Enduring/Tolerant

12. Neat/Orderly/Personal Appearance/Manner

13. Dependable/Punctual/Reliable/Responsible

14. Efficient/Quantity of Work/Achieving/Speedy

15. Dedicated/Devoted/Honest/Loyal/Conscientious

(Beach, 1978a, p. 17)

Although findings from this report are too numerous to mention in detail, some of the significant findings were that mean composite AWCI scores for

1. vocational students were greater than for academic students;

2. workers were greater than for vocational students;

3. occupational areas significantly differed;

4. female workers were significantly higher than for male workers; and

5. teachers, supervisors, and workers differed. (Beach, 1978b) 
Hales and Fenner (1972a) examined the work values of fifth-, eighth-, and eleventh-grade students in three Ohio public schools, using the Ohio Work Values Inventory (OWVI). A multivariate analysis of variance was performed, with grade level serving as the independent variable. The univariate F-ratios for Altruism and Self-Realization were significant. The fifth- and eighth-grade subjects valued altruistic jobs and work that permit self-realization less than did the eleventh-grade students.

Using the findings of various studies (Scott \& Day, 1972; Slocum \& Hand, 1971) that suggest that personality and occupational choice are related and those of other scholars that evidence a link between values and personality, Hartman (1977) studied the relationship between personality and work values. Two instruments were administered to a sample of 1,072 second-year students in two-year ohio technical colleges, the OWVI and Vocational Preference Inventory (VPI). In discussing the results of this study, Hales and Hartman (1978) suggest:

- . that people of differing personality types do tend to differ in the importance attached to various work values. Of the fifteen pair-wise comparisons, five were significant. The work values on which the pairs of personality types differed varied from pair to pair, and this variation seems to be reasonable. For example, the Realistic type placed greater value on object Orientation than did the Artistic type; the Social type placed greater value on Altruism than did the Conventional type. Consequently the expectation that personality and work values are related was supported by this study. (p. 19) 
In another study of work values, using the OWVI, A. K. Hales (1977) compared the work values of practicing nurses and nurses in training. The author states that the profile of practicing nurses is distinctive, with the scale means ranging 17 points. Practicing nurses placed considerable value on Task Satisfaction, Self-Realization, and Altruism and relatively little value on Prestige, object Orientation, and Solitude. The work values of practicing nurses did not significantly vary from those of nurse trainees. The author concluded that the measures of work values from a student nurse sample can be used to generate an occupational/professional profile.

Considerable research has been completed regarding the differences in work values according to sex. The OWVI was administered to a sample of 168 sixth-grade pupils in a southeastern Ohio town of 36,000 residents. A two-factor, multivariate analysis of variances was performed, with sex and social class as independent variables. The multivariate F-ratio was significant for sex but not for social class or interaction. Three univariate F-ratios for sex were significant. Females placed greater value on Altruism, but lesser value on Object Orientation and Solitude, than did the males (Hales \& Fenner, 1973b).

In a study of self-concept, sex, and work values, Hales and Yackee (1974) studied the responses of 99 fifthgrade pupils to the OWVI. The multivariate F-ratio and four 
univariate F-ratios for sex were significant: object orientation, Control, Ideas/Data, and Prestige. The girls placed less value than did the boys on all four.

When comparing the effect of personality, sex, and work values, Hales and Hartman (1978) performed a multivariate analysis of variance on 115 undergraduate students at Ohio University. The multivariate $F$ was significant for the sex main effect. Seven univariate F-ratios were also significant. The means for females were above the means for males on Altruism, Task Satisfaction, and SelfRealization, but were below the means for males on Control, Money, Solitude, and Prestige.

\section{Teachers and Work Values}

With the advent of career education and career awareness programs in the schools, from the elementary school level to post-secondary institutions, the world of work and the preparation of students for these positions have received widespread attention. In the late l960s the importance of developing highly effective vocational programs contributed to the rise in numbers of community colleges and the expansion of other vocational training programs. Not only did the interest in career planning change the typical vocational preparation program, but it also was helpful in redefining and analyzing the programs for professional and more traditional college-bound students in a 
variety of fields. Work and the career options became an item for study, for exploration, and for choices established after a thorough research of the desired job or profession. There has been widespread research into the reaction and importance that teachers place on career education programs. Smith (1974) studied the attitudes of teachers toward work in Tennessee. Teachers from city and country schools, 81 in each group, were administered an 18-item questionnaire. The findings showed that city teachers were more favorable than country teachers toward guidance and counseling for career development, student follow-up after graduation, work-related and hands-on experiences for teachers, and student work-study arrangements.

Both groups had $100 \%$ agreement on the following two statements:

1. Teachers should appreciate the values of many types of work.

2. Students should become familiar with many different careers. (Smith, 1974, p. 4)

Many different studies and papers address the topic of teacher attitudes toward career education. When looking for research into work values as they relate to teachers, the data is not as extensive.

A study using Super's WVI was conducted by Handley and Shill (1973). They compared the vocational education teachers' evaluation of pre-service professional training as related to their work values and attitudes toward 
students and teaching. Pre-service preparation for teaching was assessed by the Preservice Teacher Education Questionnaire, work values by the WVI, and a special scale measured attitudes toward teaching and students. The attitudes which teachers held toward their jobs and students were also significantly correlated with their own ratings of pre-service preparation. Significant relationships were discovered between the subjects' perception of their level of preparation for teaching and selected work values which they held.

A multiple correlation of .45 was found between the 15 measured work values and the attitudes which the vocational educator held toward teaching. Factors which motivated them in their job which were associated with Prestige, Surroundings, Altruism, and Way of Life were significantly related to the descriptions which teachers gave their jobs.

In a paper presented in 1981 by the Queensland Board of Teacher Education (Australia), the background characteristics, work experience, extent of contact with the world of work, and attitudes towards work of teachers in secondary schools were examined. The report summarizes the results as follows:

On the one hand, it could be argued that there is little evidence to support the contention that teachers lead an "ivory tower" existence, neither having nor wanting any direct contact with the world of work through previous employment, or having contact with other occupations as children . . . teachers considered that one means of placing more emphasis on helping students to prepare for the world of work would be to relate the curriculum to 
more practical real-life situations encountered by the students. (p. 26)

In a related discussion of teachers' attitudes toward students, Mitchell (1976) pointed out that the teachers' attitudes and judgements, whether correct or incorrect, are based on their own background and biases. Because of this innate attitude or value system, the teacher often misinterprets behaviors or differing attitudes prematurely. "An effort to change such behavior calls for awareness of its presence and its consequences. That task, in itself, is awesome" (Mitchell, 1976, p. 303).

The author continued by pointing out that teacher attitudes and expectations can affect positively or adversely student achievement, teacher behavior, and student behavior.

The crux of the matter regarding the student is, in part, whether the teacher's expectations were right or wrong, but more importantly the flexibility and adaptability of the teacher to adjust her response based on new information. (Mitchell, 1967, p. 309 )

The concept of the American work ethic is the prevalent backbone of education. Education became a prerequisite for upward mobility and a unique part of the American work ethic. Curry (1976) described the American work ethic of the past as centered around one or more of the following themes:

1. Hard work is the key to success.

2. Whatever the task you find yourself doing, do it well. 
3. Individual dignity and fulfillment in our society can only be given in and through work. ( $p$. 227)

The author continued to point to these goals as being admirable for any individual, but mostly to the benefit of society. Today the meaning and value of work are changing for many Americans. The author identified the following changes, which he sees as evolving in the new work ethic; these should have implications for all vocational and educational programs.

1. The definition and meaning of work will be redefined and broadened.

2. There will be a shift in emphasis from a goal of maximum output to utilization of maximum human potential.

3. The jobs of the future will provide for the satisfaction of higher order needs (self-esteem, social satisfaction, and self-actualization).

4. Occupations will be chosen on the basis of a realistic self-image, as awareness of the tasks involved in the occupation, and a systematic narrowing down or weeding out alternative.

5. Equal opportunity will be provided for entrance into any occupation regardless of race, sex, or age.

6. There will be revamping of values, integrity, and attitudes associated with work.

7. The labor force will move in the direction of more service-oriented occupations at a rapid rate.

8. The association of leisure time or avocational activities with the meaning of work will need to be classified. (Curry, 1976, p. 228)

In this shift from maximum production output to maximum utilization of human resources, the need for value clarification, exploration of the self, and a realistic self-image will become an integral part of the educational system (Curry, 1976). 


\section{The Teacher as a Value Builder}

The concept of a change in values along the maturation process is clearly evident and substantiated in the literature. The teacher not only instructs the child in regular curricular subjects, but the mere fact that the child will often spend more time with teachers during the day than with parents, points to the enormous responsibility the educators must assume in the building of values. Senesh (1976) comments on this idea.

Children must be taught that values exist, and that there are hierarchies in values. Teachers must point out that values can help children to build a better world--otherwise children will wander in a wasteland which we have helped to create... We must realize that the process of internalizing and applying humane values is a never ending process: the horizon is always beyond us. (p. 285)

In their discussion of what teachers can do about values, Harmin and Simon (1973) suggest that teachers have three main alternatives in dealing with value development: (1) do nothing about such development; (2) transmit a preexisting set of values to students; or (3) help students find their own values.

In choosing to do nothing about value development, the educator probably believes that this area is the domain of family and significant others in the student's life.

But the reality of schooling is that it is impossible to do nothing. When a teacher says that it is important to master a lesson to get good grades to get into college to get a good job to earn a good salary, he is obviously promoting several values-- 
a work ethic, a future orientation, and materialism, to name a few. (Harmin \& Simon, 1971)

In transmitting a pre-existing set of values to students, the educator is first faced with the question, "Are these values universal, right, desirable, or good?" Harmin and Simon (1973) offer the following approaches to transmitting values:

1. Model Approach . . people try to behave in ways that reflect the values they want to transmit.

2. Reward and Punishment Approach . . . the person first identifies desirable behavior and then, by judicious rewards, encouragement, and the like, encourages the repetition of that behavior.

3. Explanatory Approach . . . the person explains the reason for existing standards and adult beliefs.

4. Nagging Approach . . the person frequently reminds students what is right and wrong and what is expected of them without attending to whether or not the students understand the reasons for those standards.

5. Manipulation Approach . . a person manipulates environment or the experiences to which students are exposed so as to favor certain value outcomes.

6. Transmittal Liberal Arts Approach . . educators who take this approach want students to read widely, think deeply, and experience broadly. They trust that life experiences and thoughtful study provide a route to absolute values. (pp. 7-11)

In choosing the third alternative approach to value development, that of helping students find their own set of values, the previously discussed sections on value clarification apply. Most educators agree that this way of looking at values is the best for the student and will provide the optimal growth and maturation of each student. 


\section{The Teacher as a Role Model}

One of the most important factors in the development of values is that of the role models that persons have had in their lives. Kirschenbaum and Simon (1973) discuss the role of models in students' lives. They list a variety of models: parents, teachers, religious leaders, peers, sports figures, and movie, television, and recording stars. All present some type of influence and the young person has to go through a selected choosing process to sort out a variety from the various models.

We believe that teachers need to sacrifice some of their neutrality and "objectivity" and become real human beings to the students--human beings with feelings, goals, values, and contradictions they are willing to reveal and discuss, just as they would like their students to do. (Kirschenbaum \& Simon, 1973)

In discussing the relation of adolescents to nonparental adults, Elkind (1971) describes three typical patterns. The first is to treat all adults as merely extensions of the parents. Thus, the interactions of adolescents in this behavior mode would greatly depend on the relationship they have with their parents. If a child accepts and obeys the parent without question he/she is likely to react the same with other adults. Children who rebel against parental authority are likely to respond to other adults in the same manner.

Another approach is to treat adults as the opposites of parents, and to idealize them. Such people can often 
be of considerable value to the adolescent, provided they do not further undermine the parents and do not accept all the negatives about parents that the child is expounding.

The most difficult approach to handle as an adult is the one where the child assumes that adults are so different and extreme that it is impossible to communicate with them. In this situation, the positive influences the adult tries to impart to the child are greeted with hostility and fear.

Being a model is a part of teaching that no teacher can escape. Pullias and Young (1968, p. 68) describe this relationship.

Being an example arises out of the very nature of teaching, and when a teacher refuses to accept and constructively use this role he seriously reduces his effectiveness; what may be even more important, he refuses to face the reality of his situation as a teacher. This role properly conceived need not be a burden nor be, nor appear to be, presumptuous. Accepted and used with skill and humility this role greatly enriches the meaning of teaching.

oftentimes it is felt that models must be of a certain biographical makeup to be effective. In a study conducted by Freese and West (1972), the authors found that adolescents are not too concerned about the age of the teacher, the sex of the teacher, the experience of the teacher in the system, or the grade received in the course the previous semester. Adolescents seem able to consider the teacher as a person, and how the teacher interacts apart from selected personal biographical descriptors. 
The quality and power of the teacher's example vary in terms of the nature and effectiveness of the teacher... In a sense, the more effective the teacher the more powerful he is as an example. (Pullias \& Young, 1968, p. 70)

When trying to determine how teachers provide role modeling to students, the list could be extremely long. Pullias and Young list the following avenue through which example expresses the power of modeling: basic attitudes, speech and diction, work habits, attitude toward experience and mistakes, dress, human relations, thought processes, neurotic behavior, taste, judgement, health, and general style of life.

In summarizing the role of the teacher as a model, it is evident from the literature that the values held by educators do affect the students in the classroom. The values held by a teacher or educator do influence the behavior of that individual and the way that person interacts with students, other teachers, parents, and administrators.

But as a role model, the teacher is caught between two different and sometimes opposing views and sets of values. Shaver and Strong (1976, p. 71) describe the situation where educators must respond as both "agents" and "professionals."

An agent is a person empowered to act for someone else. In this sense, school people--teachers, administrators, counselors, and others-have been given the authority to carry out certain educational functions for the society. Each teacher represents the society in the classroom and during other school interactions. 
But how about citizen pressure groups? Or even more telling for the individual teacher, how about vocal parents who individually or in groups tend to exert their influence directly on the teacher rather than on the formal decision makers--school boards and legislatures? What should the impact of citizens, individually or collectively, be on your instructional decisions, especially your decisions about values?

When this pressure is combined with the teacher's role as a professional, the situation can become volatile. A . professional brings to his or her relationships expertise in a specialized area, and is backed by special knowledge and experience. A professional frequently interacts with others within a frame of ethics shaped by members of the profession. These professional roles often conflict with the agent roles a teacher encounters.

In addition to this conflict, the teacher has his or her own set of values that may be very different from either the values of the profession or those generally held by the society. Providing an atmosphere in the classroom where all values can be explored and the communication and exchange can be open is the objective for educators. Systematic review of all the influencing factors is needed to provide for an environment where students and teachers can explore their own respective values and those relating to all areas of their lives, including those relating to the world of work. 
CHAPTER III

METHODOLOGY

\section{Design of the Study}

The research design was that of a descriptive, ex post facto study. Information was collected from a sample of Oregon secondary teachers, using a written inventory and biographical sheet. The two research objectives were: (1) to determine the work values held by secondary teachers, and (2) to determine if any differences exist between teachers in a variety of teaching areas.

\section{Subjects}

Two hundred twenty Oregon certified teachers, who teach seventh through twelfth grade, were participants in this study. Separating teachers by grade level showed that 18\% taught grade seven and eight and the remainder taught ninth through twelfth grade.

Teachers from urban high schools and junior highs in the upper Willamette Valley made up the majority of the sample. Teachers from rural schools in the same area totaled 18\% of the sample. Teachers from 12 different schools provided data for this study. See Appendix E for a complete listing of specific schools. 
Prior to contacting possible participants, the researcher met with building administrators or district office personnel to explain the research study being conducted and gain approval in each district. All school districts contacted agreed to participate in the study, provided teachers could do so on a voluntary basis. In some instances, the researcher was able to meet with faculty groups to explain the study and request participation. In other cases, the principal attached a memo to the inventory, biographical sheet, and cover letter and placed the information in teachers' mailboxes. Inventories from 193 teachers were gained in this manner.

The remaining 27 subjects were gained by requesting participants in education classes at Portland State University that have a large majority of secondary teachers.

\section{Instrumentation}

The data was obtained, utilizing two instruments: a biographical data sheet and a copy of the Ohio Work Values Inventory, in booklet form.

\section{Biographical Data Sheet}

Selected demographic characteristics of the sample are reported by frequency and percentage of occurrence, for descriptive purposes, in Chapter IV. The descriptors included the following: sex, age, years of teaching experience, and area of teaching assignment (see Appendix B). 
Ohio Work Values Inventory

This section of the paper will include a discussion of the development, reliability and validity of the ohio Work Values Inventory (1973a).

Development. Fenner and Hales (1973a) said that

The Ohio Work Values Inventory (OWVI) was developed to provide a way for individuals to assess the importance they attach to those qualities of work which are personally rewarding and fullfilling. (Fenner \& Hales, 1973a, p. 1)

The concept of values has been defined in many ways. When reviewing the emergence of a value system which relates values to attitudes, needs, and interests, Fenner (1972, p. 24) indicated that values have the following characteristics:

1. They serve as judgement standards and criteria;

2 . they result from and are constantly being reconstructed within the person by means of a dynamic process;

3. they seem to involve both needs of the individual and valuations of the culture;

4. they tend to have abiding rather than transitory meaning to the person; and

5. they have generalized, inclusive, moral nature rather than specific, concrete, structured character.

The specific concept of work values has been trichotomized by both Rosenberg (1957) and Ginzberg, Axlerod, and Heime (1951). Ginzberg et al. labeled their trichotomy intrinsic, extrinsic, and concomitant. Rosenberg's categories were self-expression, things obtained from work, and interpersonal relations. Expanding these further, Super (1968) and Crites (1969) found five dimensions of work values. 
Hendrix and Super's five factors were labeled intrinsic, extrinsic, and concomitant, self-expression and autonomy.

Although there has been no agreement upon the structuring of work values, Hales and Fenner's OWVI used Ginzberg's scheme. Fenner (1972) stated that

The classificatory scheme initially proposed by Ginzberg and associated and subsequently adopted by Super offers an accurate, complete and workable system of classification. This system subdivides extrinsic values into a rewards-of-work grouping and a situate or concomitant value group. (p. 29)

Fenner and Hales (1973a, p. 8), in their manual, classified the 11 work values in the following manner. Listed also are brief descriptions of each value.

Intrinsic values

A. Altruism--helping others

B. Object Orientation--making, handling things

C. Self-Realization--using your abilities \& skills

D. Task Satisfaction--liking the tasks you do

E. Ideas/Data--using ideas, facts

Extrinsic values

A. Rewards of Work

1. Control--being in charge of others

2. Money--being paid well

3. Prestige--being known for your work

4. Security--having steady work

B. Situate

1. Independence--being your own boss

2. Solitude--not working closely with others

In discussing the criteria used in evaluating items,

Fenner and Hales (1973a, p. 2) said:

For each value, items were written, evaluated in terms of reading difficulty, singleness of interpretation, face validity, occupational orientation, clarity and generality, and submitted to field trials and revisions. 
The results of the field trials were used to revise items and to select items. Hales and Fenner (1973b, p. 2l) said, in regard to item selection, that

- . After each pilot study, correlations of each item (a) with its own scale (item set), (b) with each of other scales, and (c) with total score were obtained. To be retained for the next stage of development, an item had to exhibit a higher correlation with its own scale than with other scales and exhibit a low-to-moderate correlation with total score. Items which met these criteria were retained; other items were revised or rejected.

Reliability. Reliability studies with the OWVI indicate that the scales are reliable. Fenner and Hales (1973b, p. 2), in reporting on a study of 2,174 elementary and secondary school children, grades five to eight, said:

The results of the reliability study were favorable. . All coefficients were reasonably high for the different grade levels, for boys and girls separately within grade levels, and for different social classes. The lowest coefficient alpha was .72 for Task Satisfaction for sixth grade girls. With the exception of Task Satisfaction for the fifth and eighth grade samples, all test-retest coefficients were above .71. Most of the coefficient alphas were above .85 and most of the test-retest coefficients were above .80 .

In an unpublished study of 932 second-year students in two-year technical colleges, Hartman and Hales (1977) administered the OWVI and the VPI. Of relevance to this portion of the review, they found that coefficient alphas for the OWVI ranged from a low of .79 to a high of .94 . Validity. The primary evidence for the validity of the OWVI rests on the procedures used in constructing the scales and the subsequent subjugation of the items of the 
inventory to a factor analysis. When OWVI protocols from 1,976 subjects (fifth- through eighth-grade pupils) were submitted to a principal components analysis, using a verimax orthogonal rotation, Fenner and Hales (1973a, p. 2) found 11 factors which corresponded to the 11 scales of the OWVI. They said that:

- . the seven items of each scale appear to belong empirically as well as logically to the scale to which assigned. . . Also, evidence for construct validity of the OWVI is found in the identification of the eleven factors, with each factor corresponding to a specific scale on the instrument, and in the factor loadings of the items.

In a study by Hales and Hartman (1977, pp. 1-2), the OWVI was administered to 1,112 second-year technical college students. A principal components factor analysis was performed, using an oblique rotation. They found that the most appropriate analysis required limiting the number of factors to ten, resulting in the combination of two values (SelfRealization and Task Satisfaction).

It was decided to use a principal components approach and request 11 factors. Again, nine of the factors exhibited perfect correspondence with nine of the scales of the OWVI. . . However, the items on two scales (Self-Realization and Task Satisfaction) were confounded on two factors, the authors decided to reduce the model to 10 factors to see where the confounded items might load. All 14 items of the Self-Realization and Task Satisfaction scales loaded on the same factor. The other nine factors remained identical, in terms of the items loaded on them, with nine factors of the ll-factor model.

- - The combination of these two scales into one factor is not particularly surprising nor does it seriously affect the construct validity of the inventory. Both scales were perceived by the authors of the OWVI as two aspects of self-actualization 
as postulated in a self-theory approach to personality, and difficulty was encountered by the authors, during the construction of the inventory, in separating the two scales. Since the items logically belong where they are assigned on the two scales and since the two aspects of self-actualization are important theoretically and in terms of people's perceptions of the world of work, it is reasonable to maintain them as separate scales.

A correlational study between the scales of the OWVI and the scales of the Scales of Values by Allport, Vernon, and Lindzey (1960) was conducted by Fenner and Hales (1973b, p. 5), using a sample of 188 eleventh-grade students. The results were in general agreement with the predictions that they made.

Twenty-one of the correlations between the scale values of the OWVI and the scales on the scale of Values were significant at the .05 alpha level. - . The major findings were that those scoring high on Theoretical Man tended to value object Orientation and solitude but exhibited little valuing of Altruism and Self-Realization. The Economic Man tended to value object Orientation but not Altruism. The Aesthetic Man exhibited little valuing of Money and Prestige. The Social Man tended to value Altruism and Self-Realization, but not object Orientation, Control and Independence. The Political Man tended to value Control, Independence, Money and Prestige, but exhibited little valuing of Altruism. Finally, those scoring high on the Religious Man scale tended to value Altruism and SelfRealization, but not object Orientation. Evidence of criterion-related validity was found.

\section{$\underline{\text { Procedures }}$}

The two instruments were combined into one booklet with an accompanying cover letter (see Appendix C). Booklets and information were distributed to 460 teachers in their mailboxes or during a faculty meeting. Completed 
inventories were returned by 193 teachers, which indicated a response rate of $44 \%$. This shows a little better than the usual response of $40 \%$ expected with this type of procedure (Best, 1981, p. 168).

A follow-up reminder one week after initial contact was placed in each teacher's mailbox. No data was available as to how many teachers responded initially versus after the reminder. Teachers returned completed booklets to a box provided by the researcher that was placed in the main office of each school.

Contacts made at Portland State University were made in a similar manner. Classes were presented information and participation requested on a voluntary basis. Participants returned booklets to their instructor the following week. Fifty-six booklets were administered in this manner, with 27 returned, a response rate of $48 \%$.

Combining these two groups yielded 220 usable inventories. Eleven booklets were discarded because the participant did not answer each question on the OWVI or, in some cases, inadvertently missed an entire page.

Since booklets were placed in teacher mailboxes only, those booklets that did not have biographical data completed were added to the large teacher pool, but not used in specific small sample analysis. For those inventories that were missing part of the data, the remaining data was used whenever possible. 


\section{Statistical Methods}

Each Ohio Work Values Inventory (OWVI) was handscored by the researcher. When the scores for all 11 of the scales were completed on each participant, the biographical data and inventory scale scores were codified for computer analysis using the Statistical Package for the Social Sciences (Nie, Null, Jenkins, Steinbrenner \& Bent, 1975).

The biographical data and OWVI scale scores were analyzed for the total sample; the OWVI scale scores were also analyzed by sex and selected teaching area.

Frequency and percentage tables were constructed on the biographical data. Tables show the breakdown of the total sample by sex, age, years of teaching experience, school location, and teaching area. OWVI score frequencies with percentages were also expressed for selected teaching areas.

The means, standard deviations, and medians of the OWVI scores were calculated for the total teacher sample and expressed tabularly.

For the total sample, a multivariate analysis of variance, with the subject of teaching as the independent variable and work values as the dependent variable, was performed on OWVI scale scores. Alpha was set at .05. This procedure was used in testing the statistical hypothesis that: There will be no significant difference in work 
values among teachers within different teaching areas.

In the event that the statistical hypothesis for the multivariate analysis of variance was rejected, a univariate analysis of variance was performed on each scale, with alpha at .05 for each comparison. In each analysis of variance, in the event that the statistical hypothesis $\left(\mu_{1}=\mu_{2} \cdot \cdot \mu_{j}\right)$ was rejected, the appropriate research hypothesis that not all population means were equal was accepted. In this situation, all pair-wise mean comparisons were made, using Tukey's test for "honest significant differences" (Hopkins \& Glass, 1978, pp. 358-364). When three or more levels of an independent variable were involved, each of these comparisons took a general form of $\mu_{1}=\mu_{2}$ ' with the research hypotheses being that $\mu>\mu_{2}$ and $\mu_{1}<\mu_{2}$. The procedures described above, using teaching areas as the independent variable, were replicated to test the secondary hypothesis, using sex as the independent variable. The second statistical hypothesis was that: There will be no significant differences in work values among teachers according to their sex. 
CHAPTER IV

\section{PRESENTATION OF THE DATA \\ Description of the Sample}

The sample used in this study was drawn from 12 junior and senior high schools in Oregon. Data was collected from 220 teachers who teach seventh through twelfth grades. These schools were categorized by school location, either rural or urban (see Table I). The size of the school, as determined by pupil enrollment, ranged from 300 to 1,200 students.

\section{TABLE I}

SELECTED BIOGRAPHICAL CHARACTERISTICS OF THE SAMPLE BY SCHOOL LOCATION

\begin{tabular}{lccc}
\hline \multicolumn{1}{c}{ Location } & Frequency & Percent & $\begin{array}{r}\text { Adjusted } \\
\text { Percent }\end{array}$ \\
\hline Urban & 178 & 80.9 & 81.3 \\
Rural & 41 & 18.6 & 18.7 \\
Not Answered & 1 & 0.5 & 100.0 \\
\hline
\end{tabular}

The sample drew from a wide variety of teaching fields. The biographical data sheet used by the researcher 
listed 16 categories. There were respondents in each of the areas listed on the data sheet, with substantially higher numbers in the "core" or required subject areas. This was expected, due to the larger number of teachers employed by school districts in those subject areas (see Table II).

According to Oregon certification regulations, a teacher must be certified in a subject area that accounts for over $50 \%$ of their teaching assignment. Because of this provision, the subject area checked by each participant is the one he/she is specifically trained to teach.

The sample was categorized by sex, with exact percentages on Table III. The proportion of male to female was nearly $50 / 50$.

The average age of the study participants was 42.17 (median). The range of ages was from 23-62 years. Frequencies and percentages are listed on Table IV.

The years of teaching experience listed by participants ranged from $1-41$ years. The total sample had an average of 12.77 years of teaching experience (median) (see Table V). 
TABLE II

SELECTED BIOGRAPHICAL CHARACTERISTICS OF THE SAMPLE BY TEACHING AREA

\begin{tabular}{|c|c|c|}
\hline Teaching Area & Frequency & Percent \\
\hline Agriculture & 1 & 0 \\
\hline Art & 3 & 1 \\
\hline Business/Personal Finance & 26 & 12 \\
\hline English/Language Arts & 30 & 14 \\
\hline Foreign Language & 13 & 6 \\
\hline History & 15 & 7 \\
\hline Home Economics & 11 & 5 \\
\hline Industrial Arts/Shop & 10 & 5 \\
\hline Mathematics/Computer Science & 27 & 13 \\
\hline Music & 5 & 2 \\
\hline Physical Education/Health & 27 & 13 \\
\hline Science--Biological & 9 & 4 \\
\hline Science--General & 9 & 4 \\
\hline Science--Physical & 8 & 4 \\
\hline Special Education & 17 & 8 \\
\hline Speech/Drama & 2 & 1 \\
\hline Total & 213 & 100 \\
\hline
\end{tabular}


TABLE III

SELECTED BIOGRAPHICAL CHARACTERISTICS OF

THE SAMPLE BY SEX

\begin{tabular}{lccc}
\hline \multicolumn{1}{c}{ Sex } & Frequency & Percent & $\begin{array}{c}\text { Adjusted } \\
\text { Percent }\end{array}$ \\
\hline Male & 105 & 47.7 & 48.6 \\
Female & 111 & 50.5 & 51.4 \\
Not Answered & 4 & 1.8 & 0 \\
\hline Total & 220 & 100.0 & 100.0 \\
\hline
\end{tabular}


TABLE IV

SELECTED BIOGRAPHICAL CHARACTERISTICS OF THE SAMPLE BY AGE

\begin{tabular}{ccc}
\hline Age & Frequency & Percent \\
\hline $60-62$ & 4 & 1.9 \\
$57-59$ & 5 & 2.3 \\
$54-56$ & 9 & 4.2 \\
$51-53$ & 6 & 2.8 \\
$48-50$ & 15 & 7.0 \\
$45-47$ & 16 & 7.5 \\
$42-44$ & 27 & 12.6 \\
$39-41$ & 21 & 9.8 \\
$36-38$ & 29 & 13.6 \\
$33-35$ & 33 & 15.4 \\
$30-32$ & 26 & 12.1 \\
$27-29$ & 16 & 7.5 \\
$24-26$ & 6 & 2.8 \\
$21-23$ & 1 & .5 \\
Total & 214 & 100.0 \\
\hline
\end{tabular}

Descriptive Statistics

Mean---- - 39.39

Standard Deviation-- 8.52

Median--- - - - - 42.17 


\section{TABLE V}

SELECTED BIOGRAPHICAL CHARACTERISTICS OF THE SAMPLE BY TEACHING EXPERIENCE

\begin{tabular}{|c|c|c|}
\hline \begin{tabular}{l}
\multicolumn{2}{c}{ Years of } \\
Teaching Experience \\
\end{tabular} & Frequency & Percent \\
\hline $39-41$ & 1 & .5 \\
\hline $36-38$ & 0 & .0 \\
\hline $33-35$ & 2 & 1.0 \\
\hline $30-32$ & 7 & 3.3 \\
\hline $27-29$ & 11 & 5.2 \\
\hline $24-26$ & 9 & 4.2 \\
\hline $21-23$ & 10 & 4.7 \\
\hline $18-20$ & 20 & 9.4 \\
\hline $15-17$ & 28 & 13.1 \\
\hline $12-14$ & 31 & 14.6 \\
\hline $9-11$ & 35 & 16.4 \\
\hline $6-8$ & 27 & 12.6 \\
\hline $3-5$ & 16 & 7.5 \\
\hline $0-2$ & 16 & 7.5 \\
\hline Total & 213 & 100.0 \\
\hline
\end{tabular}

Descriptive Statistics

Mean--1-- - - 13.77

Standard Deviation-- 8.02

Median--_-_-----12.77 


\section{$\underline{\text { Principal Findings }}$}

Information included in this section falls into three major groupings. First is the descriptive data on the total teacher sample. Following that information is data and results by subject area, and this section concludes with data by sex of the teacher.

Descriptive Data: Total Teacher Sample

The OWVI scale means, standard deviations, and medians for the total teacher sample are presented in Table VI. Seven is the lowest possible score and 35 the highest. The range in mean scores was 16.182, with the range of standard deviations being 4.945 .

The values of the secondary school teachers, in order from highest to lowest perceived importance, are:

1. Task Satisfaction--liking the task you do $(33.018)$;

2. Self-Realization--using your abilities and skills $(31.736)$;

3. Altruism--helping others (28.632);

4. Ideas/Data--using ideas and facts (27.468);

5. Independence--being your own boss (26.005);

6. Security--having steady work (25.814);

7. Money--being paid well (24.864);

8. Control--being in charge of others (21.450); 
TABLE VI

SCALE MEANS AND STANDARD DEVIATIONS AND

MEDIANS OF TOTAL SAMPLE

\begin{tabular}{|c|c|c|c|}
\hline Scales & Mean & S.D. & Median \\
\hline Altruism & 28.632 & 4.778 & 29.262 \\
\hline \multicolumn{4}{|l|}{ object } \\
\hline Orientation & 18.168 & 6.928 & 16.794 \\
\hline Security & 25.814 & 5.972 & 26.192 \\
\hline Control & 21.450 & 5.970 & 21.350 \\
\hline \multicolumn{4}{|l|}{ Self- } \\
\hline Realization & 31.736 & 3.097 & 32.533 \\
\hline Independence & 26.005 & 4.974 & 26.088 \\
\hline Money & 24.864 & 7.525 & 24.944 \\
\hline \multicolumn{4}{|l|}{ Task } \\
\hline Satisfaction & 33.018 & 2.580 & 34.071 \\
\hline Solitude & 16.836 & 5.248 & 16.767 \\
\hline Ideas/Data & 27.468 & 4.819 & 27.935 \\
\hline Prestige & 18.895 & 6.426 & 18.571 \\
\hline
\end{tabular}


9. Prestige--being known for your own work (18.895);

10. Object Orientation--making, handling things $(18.168) ;$ and

11. Solitude--not working closely with others $(16.836)$.

(The brief descriptors of each value above are from Hales \& Fenner, 1973a, p. 2.)

Scale scores, frequencies, and percentages for each of the 11 values for the total teacher sample on the OWVI are listed on Tables VII-XVII. Also given are means, standard deviations, and medians for each value.

\section{Data: By Subject Area}

OWVI scale-\$core percentages and means were calculated for all teaching qreas with 10 or more participants. In some cases, several similar subjects were grouped together. These groupings are footnoted on the tables for each subject area which are found in Appendix D. Summary information of mean values on each subject area is found on Table XVIII.

OWVI scale-score rankings by subject area are in Table XIX. All subject areas ranked Task Satisfaction and SelfRealization at the top of the given values related to work. The means between groups were relatively close in both of these areas, with a range of 3.08 and 3.41 respectively. 
TABLE VII

TEACHER SCALE SCORES FOR ALTRUISM

\begin{tabular}{|c|c|c|c|}
\hline Score & Frequency & Percent & $\begin{array}{c}\text { Cumulative } \\
\text { Percent }\end{array}$ \\
\hline 35 & 18 & 8 & 100 \\
\hline 34 & 19 & 9 & 92 \\
\hline 33 & 12 & 5 & 83 \\
\hline 32 & 22 & 10 & 78 \\
\hline 31 & 31 & 10 & 68 \\
\hline 30 & 13 & 6 & 58 \\
\hline 29 & 21 & 10 & 52 \\
\hline 28 & 12 & 5 & 43 \\
\hline 27 & 16 & 7 & 37 \\
\hline 26 & 15 & 7 & 30 \\
\hline 25 & 11 & 5 & 23 \\
\hline 24 & 9 & 4 & 18 \\
\hline 23 & 9 & 4 & 18 \\
\hline 22 & 6 & 3 & 10 \\
\hline 21 & 4 & 2 & 7 \\
\hline 20 & 2 & 1 & 5 \\
\hline 19 & 2 & 1 & 5 \\
\hline 18 & 1 & 0 & 4 \\
\hline 17 & 5 & 2 & 3 \\
\hline 16 & 0 & 0 & 1 \\
\hline 15 & 0 & 0 & 1 \\
\hline 14 & 0 & 0 & 1 \\
\hline 13 & 0 & 0 & 1 \\
\hline 12 & 1 & 0 & 1 \\
\hline 11 & $\overline{0}$ & 0 & 0 \\
\hline 10 & 0 & 0 & 0 \\
\hline 9 & 0 & 0 & 0 \\
\hline 8 & 1 & 0 & 0 \\
\hline
\end{tabular}

Descriptive Statistics

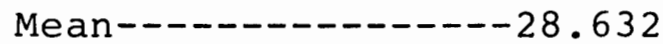

Standard Deviation-- 4.778

Median---_-_-_----29.262 
TABLE VIII

TEACHER SCALE SCORES FOR OBJECT ORIENTATION

\begin{tabular}{|c|c|c|c|}
\hline Score & Frequency & Percent & $\begin{array}{c}\text { Cumulative } \\
\text { Percent }\end{array}$ \\
\hline 35 & 5 & 2 & 100 \\
\hline 34 & 1 & 0 & 98 \\
\hline 33 & 2 & 1 & 97 \\
\hline 32 & 1 & 0 & 96 \\
\hline 31 & 3 & 1 & 96 \\
\hline 30 & 4 & 2 & 95 \\
\hline 29 & 4 & 2 & 93 \\
\hline 28 & 8 & 4 & 91 \\
\hline 27 & 8 & 4 & 87 \\
\hline 26 & 4 & 2 & 84 \\
\hline 25 & 5 & 2 & 82 \\
\hline 24 & 4 & 2 & 80 \\
\hline 23 & 5 & 2 & 78 \\
\hline 22 & 7 & 3 & 75 \\
\hline 21 & 16 & 7 & 72 \\
\hline 20 & 9 & 4 & 65 \\
\hline 19 & 5 & 2 & 61 \\
\hline 18 & 7 & 3 & 59 \\
\hline 17 & 17 & 8 & 55 \\
\hline 16 & II & 5 & 48 \\
\hline 15 & 19 & 9 & 43 \\
\hline 14 & 17 & 8 & 34 \\
\hline 13 & 12 & 5 & 26 \\
\hline 12 & 6 & 3 & 21 \\
\hline 11 & 12 & 5 & 18 \\
\hline 10 & 8 & 4 & 13 \\
\hline 9 & 6 & 3 & 9 \\
\hline 8 & 10 & 5 & 6 \\
\hline 7 & 4 & 2 & 2 \\
\hline
\end{tabular}

Descriptive Statistics

Mean-- - - - 18.168

Standard Deviation-- 6.928

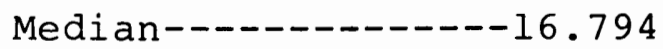


TABLE IX

TEACHER SCALE SCORES FOR SECURITY

\begin{tabular}{|c|c|c|c|}
\hline Score & Frequency & Percent & $\begin{array}{c}\text { Cumulative } \\
\text { Percent }\end{array}$ \\
\hline 35 & 18 & 8 & 100 \\
\hline 34 & 9 & 4 & 92 \\
\hline 33 & 10 & 5 & 88 \\
\hline 32 & 13 & 6 & 83 \\
\hline 31 & 10 & 5 & 77 \\
\hline 30 & 6 & 3 & 73 \\
\hline 29 & 1 & 0 & 70 \\
\hline 28 & 20 & 9 & 70 \\
\hline 27 & 19 & 9 & 60 \\
\hline 26 & 13 & 6 & 52 \\
\hline 25 & 15 & 7 & 46 \\
\hline 24 & 2 & $i$ & 39 \\
\hline 23 & 9 & 4 & 38 \\
\hline 22 & 21 & 10 & 34 \\
\hline 21 & 16 & 7 & 25 \\
\hline 20 & 8 & 4 & 17 \\
\hline 19 & 8 & 4 & 14 \\
\hline 18 & 2 & 1 & 10 \\
\hline 17 & 2 & 1 & 9 \\
\hline 16 & 7 & 3 & 8 \\
\hline 15 & 5 & 2 & 5 \\
\hline 14 & 1 & 0 & 3 \\
\hline 13 & 2 & 1 & 2 \\
\hline 12 & 1 & 0 & 1 \\
\hline 11 & 0 & 0 & 1 \\
\hline 10 & 0 & 0 & 1 \\
\hline 9 & 2 & 1 & 1 \\
\hline
\end{tabular}

Descriptive Statistics

Mean------------25.814

Standard Deviation-- 5.972

Median---_--_----26.192 
TABLE X

TEACHER SCALE SCORES FOR CONTROL

\begin{tabular}{cccc}
\hline & & & \\
Score & Frequency & Percent & $\begin{array}{c}\text { Cumulative } \\
\text { Percent }\end{array}$ \\
\hline 35 & 3 & 1 & 100 \\
34 & 4 & 2 & 99 \\
33 & 2 & 1 & 97 \\
32 & 3 & 1 & 96 \\
31 & 1 & 0 & 95 \\
30 & 5 & 2 & 94 \\
29 & 5 & 2 & 92 \\
28 & 10 & 5 & 90 \\
27 & 14 & 6 & 85 \\
26 & 12 & 5 & 79 \\
25 & 7 & 3 & 73 \\
24 & 12 & 5 & 65 \\
23 & 15 & 7 & 58 \\
22 & 14 & 6 & 51 \\
21 & 20 & 9 & 42 \\
20 & 21 & 10 & 33 \\
19 & 11 & 5 & 28 \\
18 & 5 & 2 & 25 \\
17 & 7 & 3 & 22 \\
16 & 12 & 5 & 17 \\
15 & 8 & 4 & 13 \\
14 & 5 & 2 & 11 \\
13 & 7 & 3 & 8 \\
12 & 3 & 1 & 6 \\
11 & 4 & 2 & 5 \\
10 & 5 & 2 & 2 \\
9 & 3 & 1 & 1 \\
8 & 2 & 1 & \\
& 15 & & \\
\hline
\end{tabular}

Descriptive Statistics

Mean----_-_------21.450

Standard Deviation-- 5.970

Median--_---_----21.350 
TABLE XI

TEACHER SCALE SCORES FOR SELF-REALIZATION

\begin{tabular}{cccc}
\hline Score & Frequency & Percent & $\begin{array}{c}\text { Cumulative } \\
\text { Percent }\end{array}$ \\
\hline 35 & 58 & 26.4 & 100 \\
34 & 23 & 10.5 & 73.6 \\
33 & 30 & 13.6 & 63.2 \\
32 & 19 & 8.6 & 49.5 \\
31 & 20 & 9.1 & 40.9 \\
30 & 17 & 7.7 & 31.8 \\
29 & 14 & 6.4 & 24.1 \\
28 & 11 & 5.0 & 17.7 \\
27 & 17 & 7.7 & 12.5 \\
26 & 5 & 2.3 & 5.0 \\
25 & 1 & 0.5 & 2.7 \\
24 & 1 & 0.5 & 2.3 \\
23 & 3 & 1.4 & 1.8 \\
22 & 0 & 0 & 0.5 \\
21 & 1 & 0.5 & \\
\hline
\end{tabular}

Descriptive Statistics

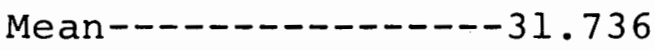

Standard Deviation-- 3.097

Median--_---32.533 
TABLE XII

TEACHER SCALE SCORES FOR INDEPENDENCE

\begin{tabular}{|c|c|c|c|}
\hline Score & Frequency & Percent & $\begin{array}{c}\text { Cumulative } \\
\text { Percent }\end{array}$ \\
\hline $\begin{array}{l}35 \\
34 \\
33 \\
32 \\
31 \\
30 \\
29 \\
28 \\
27 \\
26 \\
25 \\
24 \\
23 \\
22 \\
21 \\
20 \\
19 \\
18 \\
17 \\
16 \\
15 \\
14\end{array}$ & $\begin{array}{r}9 \\
11 \\
8 \\
7 \\
5 \\
16 \\
14 \\
13 \\
20 \\
17 \\
18 \\
15 \\
11 \\
9 \\
12 \\
14 \\
6 \\
7 \\
3 \\
1 \\
1 \\
3\end{array}$ & $\begin{array}{l}4 \\
5 \\
4 \\
3 \\
2 \\
7 \\
6 \\
6 \\
9 \\
8 \\
8 \\
7 \\
5 \\
4 \\
5 \\
6 \\
3 \\
3 \\
1 \\
0 \\
0 \\
1\end{array}$ & $\begin{array}{r}100 \\
96 \\
91 \\
87 \\
84 \\
82 \\
75 \\
68 \\
62 \\
53 \\
45 \\
37 \\
30 \\
25 \\
21 \\
16 \\
10 \\
7 \\
4 \\
2 \\
2 \\
1\end{array}$ \\
\hline \multicolumn{4}{|c|}{ Descriptive statistics } \\
\hline \multicolumn{4}{|c|}{$\begin{array}{l}\text { Standard Deviation-- } 4.974 \\
\text { Median--- }\end{array}$} \\
\hline
\end{tabular}


TABLE XIII

TEACHER SCALE SCORES FOR MONEY

\begin{tabular}{|c|c|c|c|}
\hline Score & Frequency & Percent & $\begin{array}{c}\text { Cumulative } \\
\text { Percent }\end{array}$ \\
\hline 35 & 29 & 13 & 100 \\
\hline 34 & 11 & 5 & 87 \\
\hline 33 & 12 & 5 & 82 \\
\hline 32 & 13 & 6 & 76 \\
\hline 31 & 4 & 2 & 70 \\
\hline 30 & 5 & 2 & 69 \\
\hline 29 & 6 & 3 & 66 \\
\hline 28 & 15 & 7 & 64 \\
\hline 27 & 5 & 2 & 57 \\
\hline 26 & 5 & 2 & 55 \\
\hline 25 & 9 & 4 & 52 \\
\hline 24 & 5 & 2 & 48 \\
\hline 23 & 7 & 3 & 46 \\
\hline 22 & 6 & 3 & 43 \\
\hline 21 & 21 & 10 & 40 \\
\hline 20 & 9 & 4 & 30 \\
\hline 19 & 3 & 1 & 26 \\
\hline 18 & 10 & 5 & 25 \\
\hline 17 & 5 & 2 & 20 \\
\hline 16 & 10 & 5 & 18 \\
\hline 15 & 10 & 5 & 14 \\
\hline 14 & 7 & 3 & 9 \\
\hline 13 & 3 & 1 & 6 \\
\hline 12 & 3 & 1 & 5 \\
\hline 11 & 4 & 2 & 3 \\
\hline 10 & 1 & 0 & 1 \\
\hline 9 & 2 & 1 & 1 \\
\hline
\end{tabular}

Descriptive Statistics

Mean--D-n---o---24.864

Standard Deviation-- 7.525

Median--_-_-----24.944 
TABLE XIV

TEACHER SCALE SCORES FOR TASK SATISFACTION

\begin{tabular}{cccc}
\hline Score & Frequency & Percent & $\begin{array}{c}\text { Cumulative } \\
\text { Percent }\end{array}$ \\
\hline 35 & 95 & 43.2 & 100 \\
34 & 35 & 15.9 & 56.8 \\
33 & 21 & 9.5 & 40.9 \\
32 & 19 & 8.6 & 31.4 \\
31 & 14 & 6.4 & 22.7 \\
30 & 12 & 5.5 & 16.4 \\
29 & 6 & 2.7 & 10.9 \\
28 & 8 & 3.6 & 8.2 \\
27 & 3 & 1.4 & 4.5 \\
26 & 3 & 1.4 & 3.2 \\
25 & 2 & 0.9 & 1.8 \\
24 & 1 & 0.5 & 0.9 \\
23 & 1 & 0.5 & 0.5 \\
& & & 5 \\
\hline
\end{tabular}

Descriptive statistics

Mean-- - - - - -018

Standard Deviation-- 2.580

Median----------- 34.071 
TABLE XV

TEACHER SCALE SCORES FOR SOLITUDE

\begin{tabular}{|c|c|c|c|}
\hline Score & Frequency & Percent & $\begin{array}{c}\text { Cumulative } \\
\text { Percent }\end{array}$ \\
\hline 31 & 2 & 1 & 100 \\
\hline 30 & 2 & 1 & 99 \\
\hline 29 & 0 & 0 & 98 \\
\hline 28 & 3 & 1 & 98 \\
\hline 27 & 4 & 2 & 97 \\
\hline 26 & 3 & 1 & 95 \\
\hline 25 & 4 & 2 & 94 \\
\hline 24 & 7 & 3 & 92 \\
\hline 23 & 7 & 3 & 89 \\
\hline 22 & 8 & 4 & 85 \\
\hline 21 & 14 & 6 & 82 \\
\hline 20 & 10 & 5 & 75 \\
\hline 19 & 14 & 6 & 71 \\
\hline 18 & 21 & 10 & $6 \overline{5}$ \\
\hline 17 & 15 & 7 & 55 \\
\hline 16 & 10 & 5 & 48 \\
\hline 15 & 16 & 7 & 44 \\
\hline 14 & 13 & 6 & 36 \\
\hline 13 & 14 & 6 & 30 \\
\hline 12 & 17 & 8 & 24 \\
\hline 11 & 11 & 5 & 16 \\
\hline 10 & 9 & 4 & 11 \\
\hline 9 & 10 & 5 & 7 \\
\hline 8 & 3 & 1 & 3 \\
\hline 7 & 3 & 1 & 1 \\
\hline \multicolumn{4}{|c|}{ Descriptive Statistics } \\
\hline \multicolumn{4}{|c|}{ Mean----n---16.836 } \\
\hline \multicolumn{4}{|c|}{ Standard Deviation-- 5.248} \\
\hline & \multicolumn{3}{|c|}{ Median-----------16.767 } \\
\hline
\end{tabular}


TABLE XVI

TEACHER SCALE SCORES FOR IDEAS/DATA

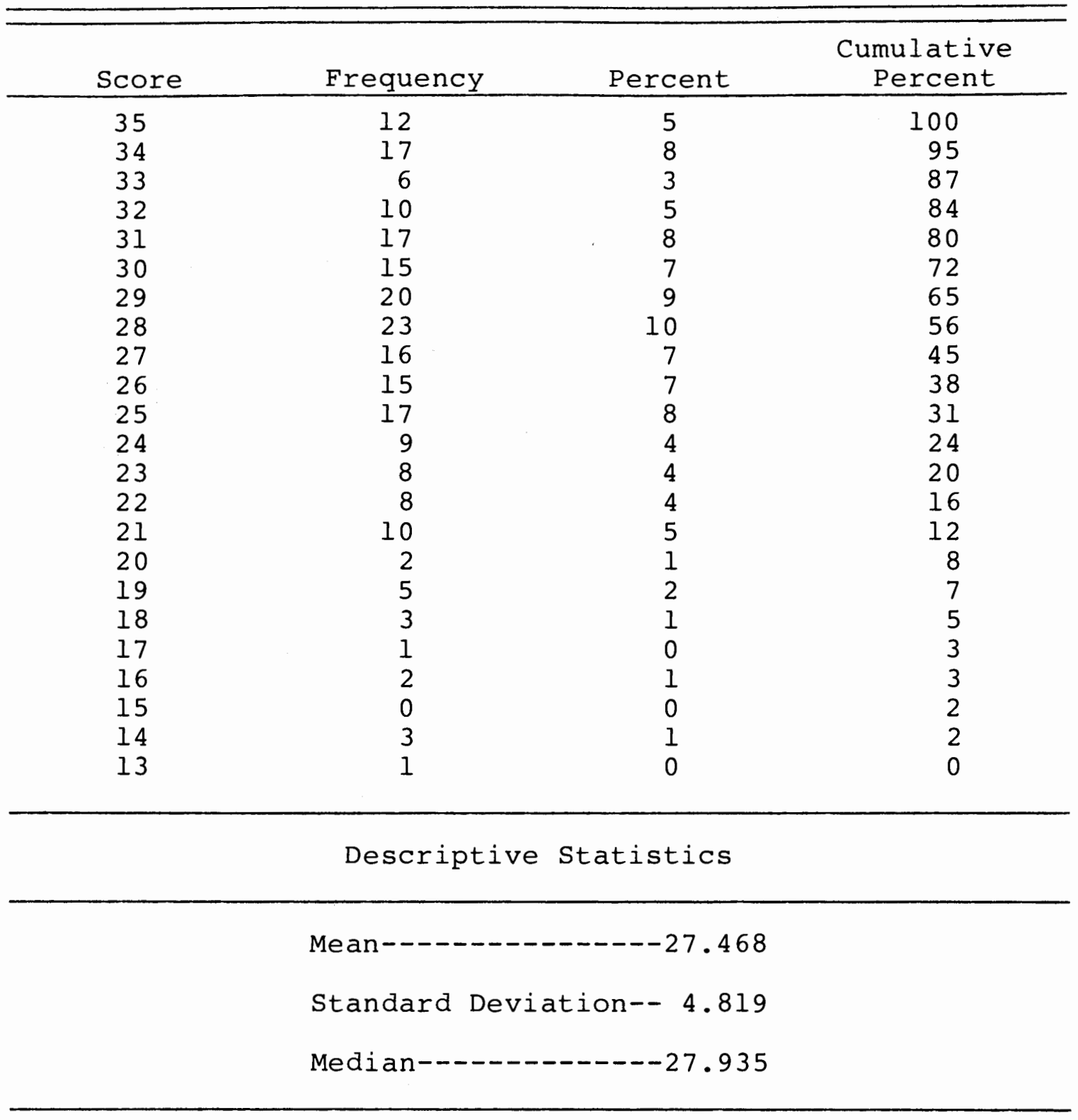


TABLE XVII

TEACHER SCALE SCORES FOR PRESTIGE

\begin{tabular}{|c|c|c|c|}
\hline Score & Frequency & Percent & $\begin{array}{c}\text { Cumulative } \\
\text { Percent }\end{array}$ \\
\hline 35 & 4 & 2 & 100 \\
\hline 34 & 2 & 1 & 98 \\
\hline 33 & 2 & 1 & 97 \\
\hline 32 & 1 & 0 & 96 \\
\hline 31 & 2 & 1 & 96 \\
\hline 30 & 1 & 0 & 95 \\
\hline 29 & 3 & 1 & 95 \\
\hline 28 & 7 & 3 & 93 \\
\hline 27 & 8 & 4 & 90 \\
\hline 26 & 9 & 4 & 86 \\
\hline 25 & 4 & 2 & 82 \\
\hline 24 & 8 & 4 & 80 \\
\hline 23 & 7 & 3 & 77 \\
\hline 22 & 10 & 5 & 74 \\
\hline 21 & 15 & 7 & 69 \\
\hline 20 & 14 & 6 & 62 \\
\hline 19 & 14 & 6 & 56 \\
\hline 18 & 14 & 6 & 50 \\
\hline 17 & 10 & 5 & 43 \\
\hline 16 & 15 & 7 & 39 \\
\hline 15 & 14 & 6 & 32 \\
\hline 14 & 10 & 5 & 25 \\
\hline 13 & 4 & 2 & 21 \\
\hline 12 & 10 & 5 & 19 \\
\hline 11 & 11 & 5 & 15 \\
\hline 10 & 8 & 4 & 10 \\
\hline 9 & 5 & 2 & 6 \\
\hline 8 & 6 & 3 & 4 \\
\hline 7 & 2 & 1 & 1 \\
\hline
\end{tabular}

Descriptive Statistics

Mean--D-n----18.895

Standard Deviation-- 6.426

Median-----_-----18.571 


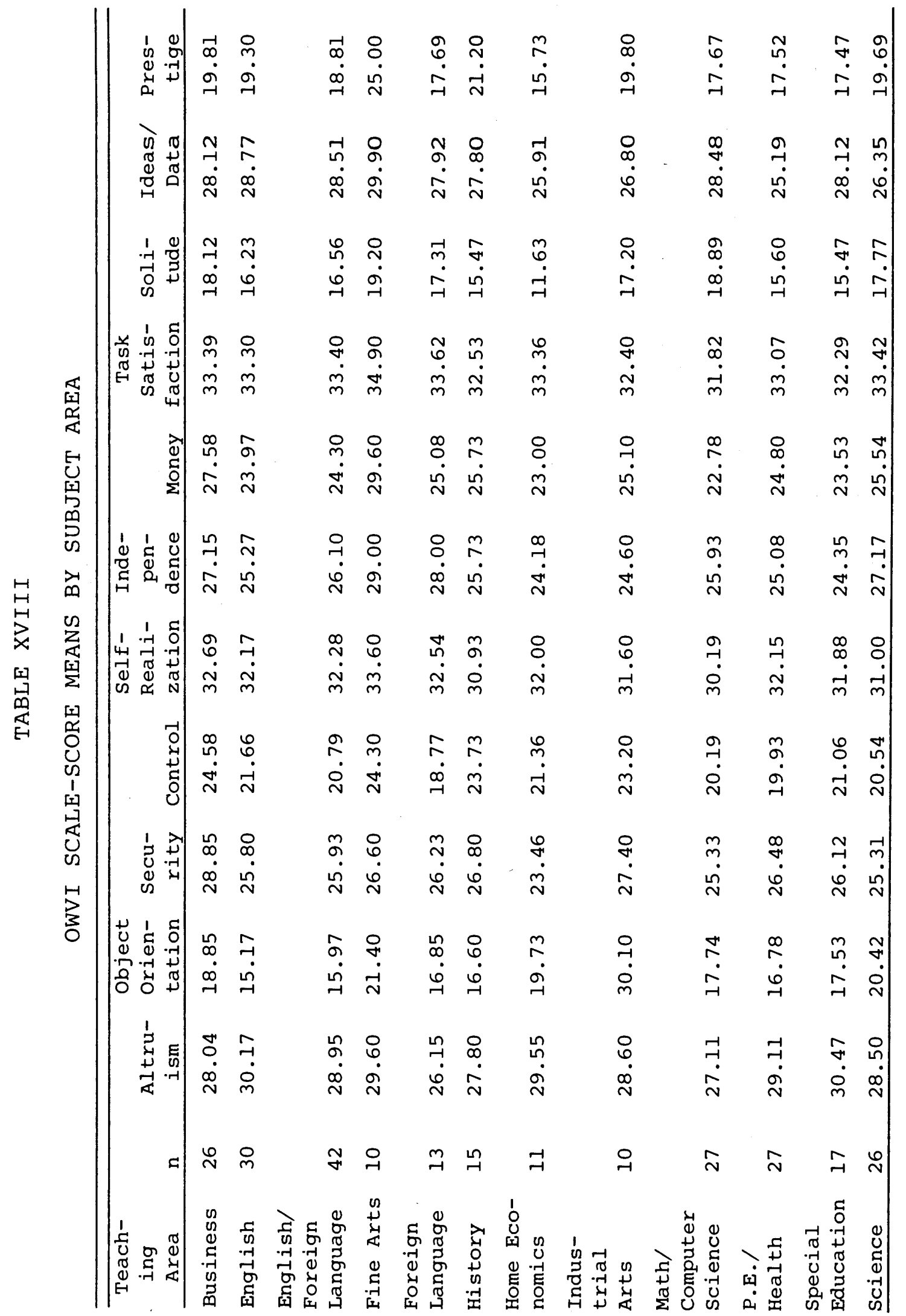




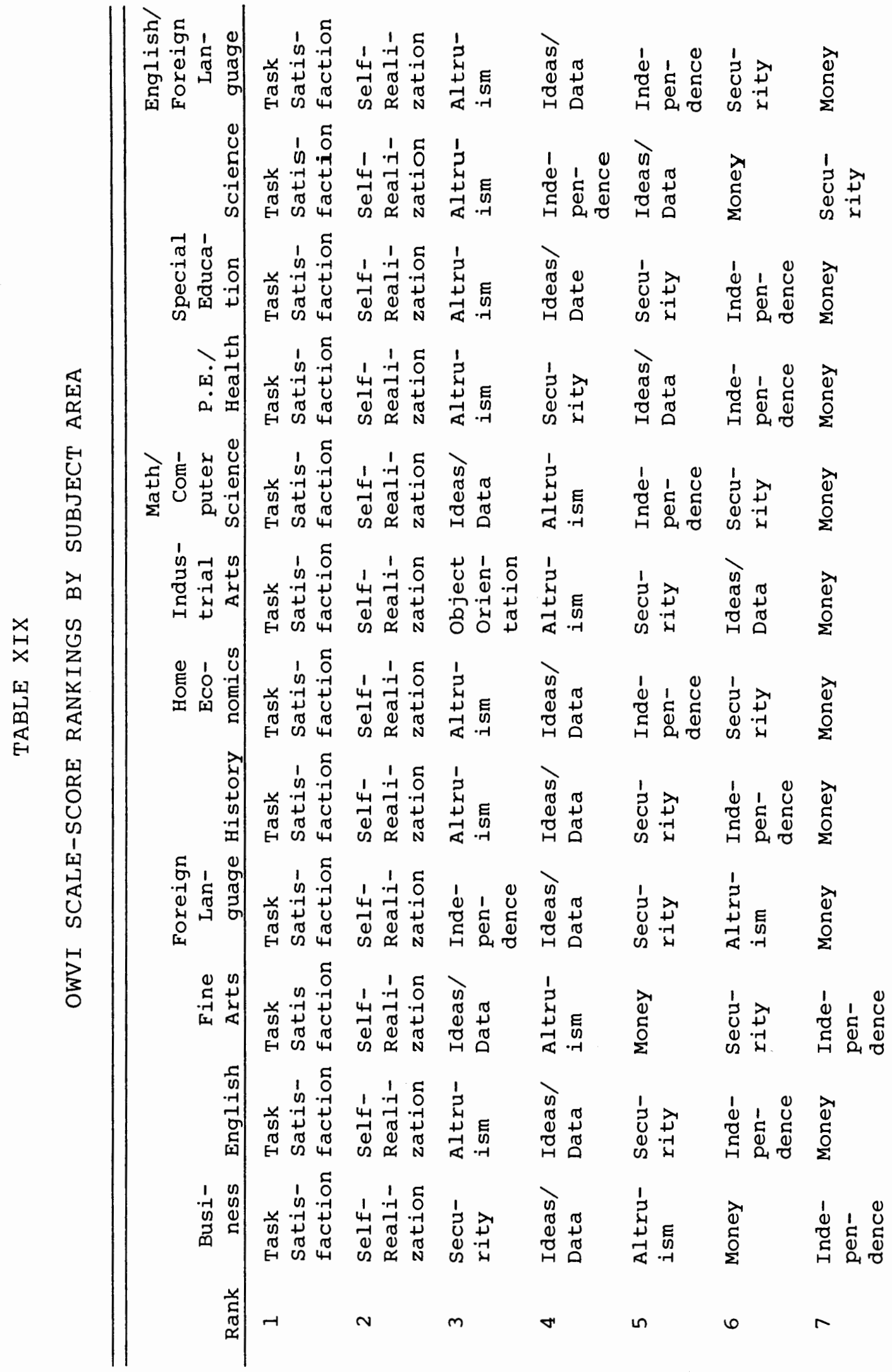




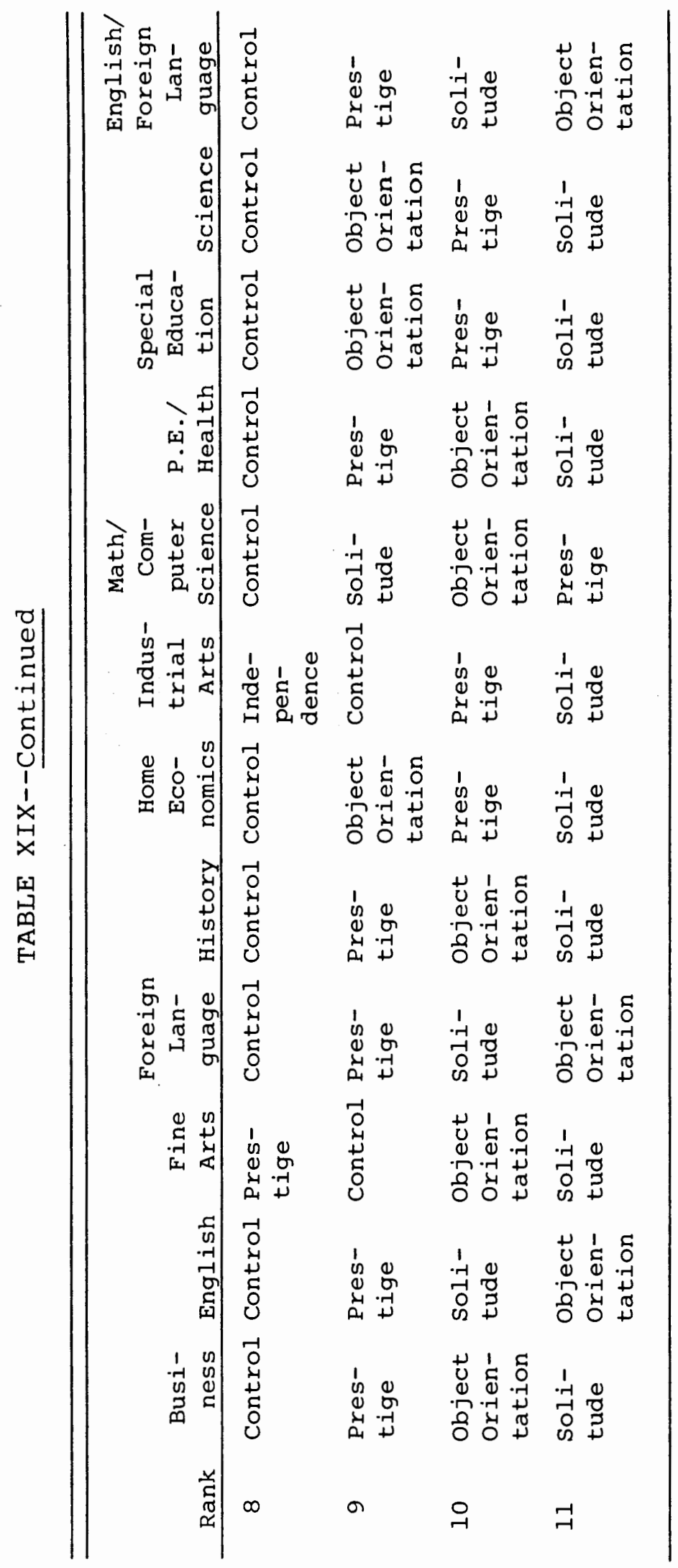


Altruism, helping others, was listed by six of the teaching fields as their third value priority. Business teachers listed Security; Foreign Language teachers listed Independence; Industrial Arts teachers listed Object Orientation; and Ideas/Data was valued third by both Fine Arts and Math/Computer Science teachers.

Solitude was listed as the least important by eight of the teaching fields. Math/Computer Science teachers placed Prestige last, and Object Orientation placed last with both English and Foreign Language teachers. Prestige and object orientation placed near the bottom, by priority, on most all teacher groupings.

A multivariate analysis of variance was performed with teaching (subject) areas as the independent variable and the scales of the OWVI as the dependent variable. Groupings for this analysis were: Math/Computer Science, Science, English/Foreign Language, P.E./Health, Business, History, and Special Education.

The $F$ value for the Hotellings' test was 1.374 ; this was significant at the .05 level $\underline{p}=.029)$. Therefore, the statistical hypothesis was rejected, and univariate analyses of variance were performed on the 11 dependent variables (see Table XX).

Two statistical hypotheses were rejected at the .05 level. Significant differences were found among the groups for Control $\underline{p}=.0259$ ) and Self-Realization $\underline{p}=.0310$ ). 


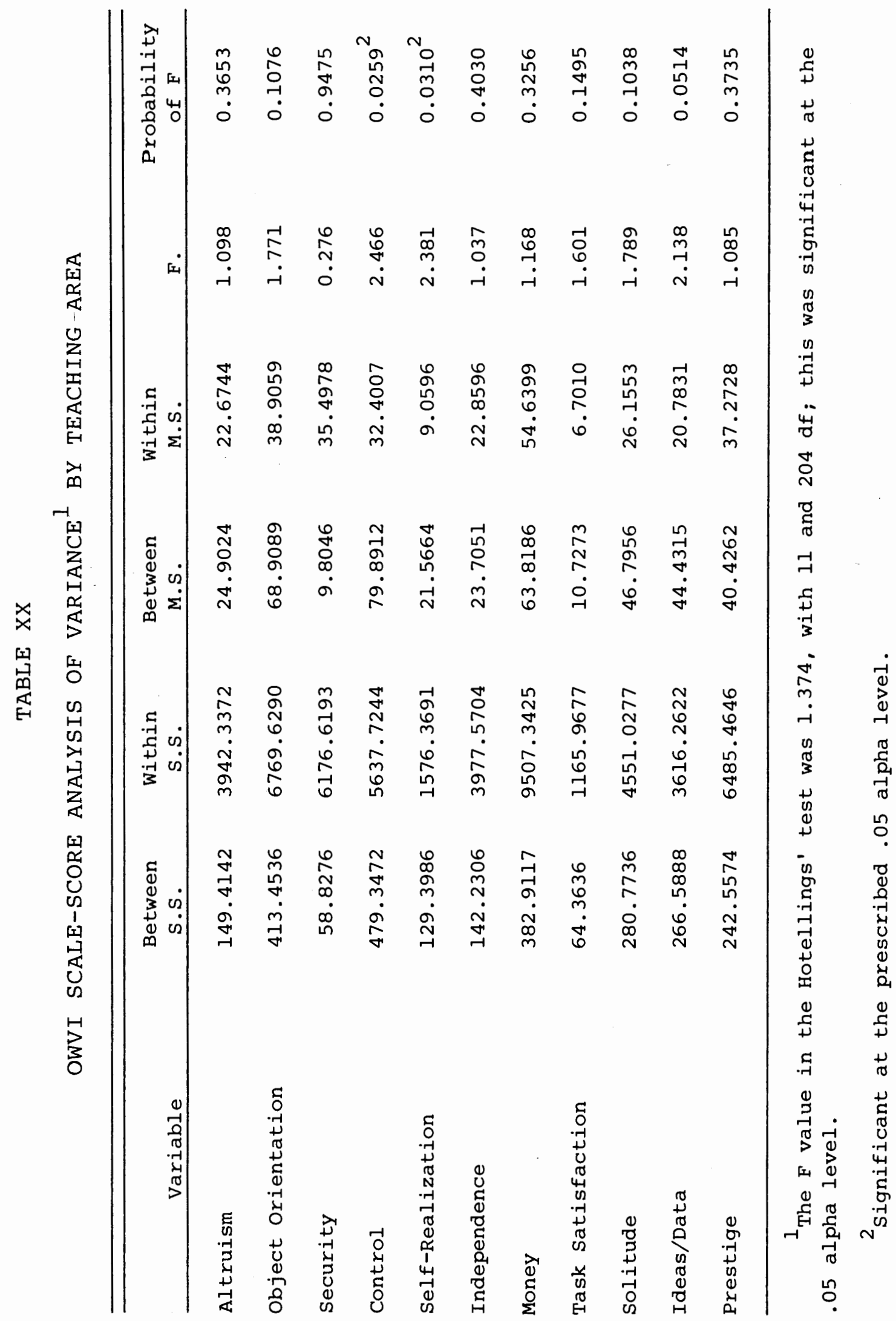


All pair-wise mean comparisons were performed on these two variables, using Tukey's HSD method, with alpha set at .05. One statistical hypothesis was rejected in the pair-wise comparisons of means. Math/Computer Science teachers placed lesser value on Self-Realization than did Business teachers. No other differences were found in the pair-wise mean comparisons.

Data: By Sex of the Teacher

Scale means for all 11 values by sex are listed on Table XXI. A multivariate analysis of variance was performed, with sex as the independent variable and the scales of the OWVI as the dependent variable. The $F$ value for Hotellings' test was 5.359; this was significant at the .05 level $\underline{p}=.000)$.

TABLE XXI

OWVI SCALE-SCORE MEANS BY SEX OF THE TEACHER

\begin{tabular}{lcc}
\hline & \multicolumn{2}{c}{ OWVI Scale Means } \\
\cline { 2 - 3 } Variable & $\begin{array}{c}\text { Male } \\
(\mathrm{n}=105)\end{array}$ & $\begin{array}{c}\text { Female } \\
(\mathrm{n}=111)\end{array}$ \\
\hline Altruism & 28.37 & 28.90 \\
Object Orientation & 20.70 & 15.96 \\
Security & 26.25 & 25.68 \\
Control & 21.59 & 21.54 \\
Self-Realization & 31.33 & 32.24 \\
Independence & 26.64 & 25.57 \\
Money & 25.01 & 24.95 \\
Task Satisfaction & 32.72 & 33.32 \\
Solitude & 17.88 & 15.91 \\
Ideas/Data & 27.90 & 27.17 \\
Prestige & 19.99 & 18.13 \\
\hline
\end{tabular}


The statistical hypothesis was rejected, and univariate analyses of variance were performed on the 11 dependent variables (see Table XXII). Four statistical hypotheses were rejected at the .05 level. Significant differences were found on Object Orientation, Solitude, Prestige, and SelfRealization, with female teachers placing lesser value on the first three and greater value on the Self-Realization value than did the male teachers. 


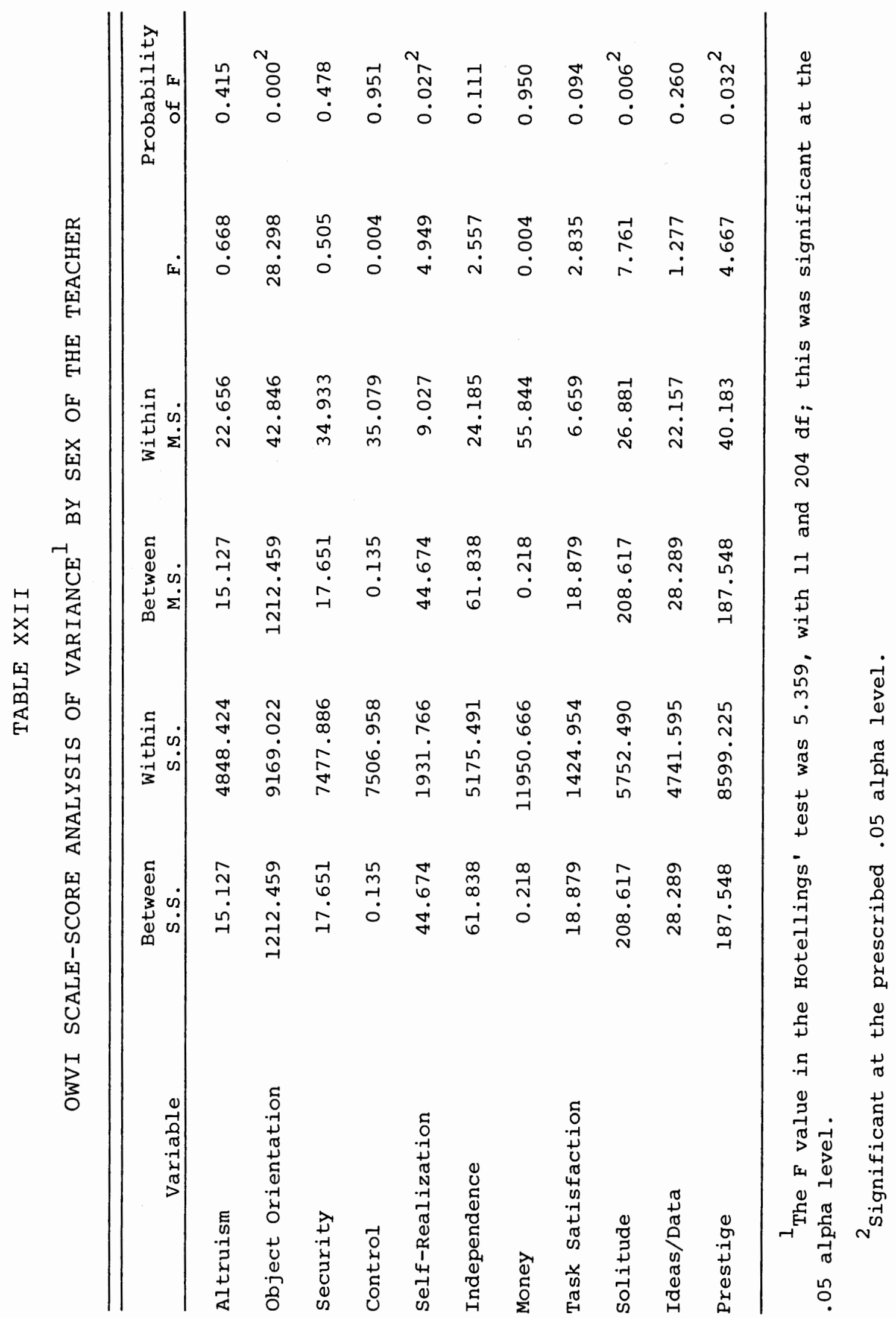




\section{CHAPTER V}

\section{ANALYSIS OF DATA}

\section{Summary of the Study}

The major focus of this study was to determine the work values held by secondary teachers. The secondary analysis involved a comparison of work values held by teachers in varying subject areas, and comparison by sex of the teacher. The sample consisted of 220 Oregon teachers, seventh through twelfth grades, located in 12 Upper willamette Valley rural and urban secondary schools. The teachers had a median age of 42.17 and were split $48 \%$ male and $51 \%$ female. The median years of teaching experience was 12.77 years.

The study participants were all administered the OWVI and a biographical data sheet. The biographical data was listed by frequency and percent. The OWVI scale means, standard deviations, and medians were calculated for the entire sample. Frequency and percentages were also listed for each of the 11 OWVI scales.

The range of means for the teacher sample on the OWVI scales was 16.182 points. Task Satisfaction (33.018), SelfRealization (31.736), and Altruism (28.632) were valued the 
most by secondary teachers. Prestige (18.895), Object Orientation (18.168), and Solitude (16.836) were valued the least.

Scale-score percentages were calculated on selected teaching fields. Task Satisfaction and Self-Realization were valued the most by all teaching groups. The remaining values varied by ranking, with Solitude, Prestige, and Object Orientation placing in the last three positions on most priority listings of teachers by subject area.

A multivariate analysis of variance was performed with subject areas as the independent variable and the scales of the OWVI as the dependent variable. The statistical hypothesis was rejected, and univariate analyses of variance were performed on the 11 dependent variables.

Two statistical hypotheses were rejected at the .05 level. Significant differences were found among groups for Control and Self-Realization. All pair-wise mean comparisons were performed on these two variables, with one statistical hypothesis rejected in the pair-wise comparisons of means. Math/Computer Science teachers placed lesser value on Self-Realization than did Business teachers.

Scale means were listed by sex of the teacher. A multivariate analysis of variance was performed with sex as the independent variable and the OWVI scales as the dependent variable. The statistical hypothesis was rejected, and univariate analyses of variance were performed on the 
11 dependent variables, with four being rejected at the .05 level. Significant differences were found; female teachers placed more value on Self-Realization. Males placed significantly higher value on Solitude, Prestige, and object Orientation than did the female teachers.

\section{Conclusions}

The Ohio Work Values Inventory can be used to measure the work values of secondary teachers. The profile of the secondary teacher is distinctive, with a range of 16.182 points. Task Satisfaction, Self-Realization, and Altruism were valued the most, and Prestige, object Orientation, and Solitude the least.

This ordering closely parallels the results of A. K. Hale's (1977) practicing nurses' sample, the majority of which were employed in Ohio. When the OWVI scale means were ranked for the nursing sample and for the high school teacher sample, the Spearman rank order coefficient was +.96; nevertheless, the absolute strength (magnitude of means) differed between the two samples from scale to scale. It would appear that nurses in the previous study, the teachers from this sample, and perhaps other helping professions have somewhat similar profiles in regard to the shape.

In the comparison of the work values of teachers in seven teaching fields, the statistical hypothesis for the multivariate and two univariate analyses of variance were 
rejected, but only one of the statistical hypotheses for pair-wise mean comparisons was rejected. The Oregon secondary teachers in different subject fields, from this Oregon sample, seem to hold somewhat different values, but the constriction of sample size and number of groups compared on the statistical test did not permit one identification of these differences. A visual inspection of the profiles suggests that there may be clusters of fields in which the teachers, within the fields of a cluster, hold similar values to one another.

The results of this study with regards to differences of work values between males and females follow and support earlier research with this instrument. Secondary teachers varied by sex on four of the values. Female teachers placed higher value on Self-Realization and males showed a higher value for Object Orientation, Solitude, and Prestige. Hales and Hartman's (1978) study of undergraduate students found significant differences on seven of the univariate ratios. The means for females were above the means for males on Altruism, Task Satisfaction, and Self-Realization, but were below the means for males on Control, Money, Solitude, and Prestige.

Hales and Yackee (1974) and Hales and Fenner (1973) all showed differences between the sexes. It should be noted that these two studies were performed on elementary 
school children, which supports the fact that differences in value orientations are visible early in life.

\section{Recommendations for Further Research}

From the research and conceptualization of a number of scholars, it may be concluded that the values which people hold influence their behavior (Shaver \& Larkins, 1969, 1973; Rokeach, 1973) and that teachers serve as role models for their students (Pullias \& Young, 1968; Freese \& West, 1972; Kirschenbaum \& Simon, 1973), often contributing to the development of the values and value systems of their students (Harmin \& Simon, 1971; Senesh, 1976).

Since the results of this study indicate that secondary teachers in general present a work values profile which is high on Task Satisfaction, Self-Realization, and Altruism and relatively low on Object Orientation and Solitude, if teachers are indeed serving as role models, then one might expect that students will be influenced in the direction of their teachers' values.

This may be somewhat modified, exerting a differential modifying influence as a result of differences in profile among teachers, particularly since there is reason to believe these differences cluster somewhat around teaching disciplines. Nevertheless, these results suggest that it is important for teachers to be aware of their own work values, so as not'to unknowingly convey approval/disapproval 
of various work values, and that the curriculum should provide an opportunity for students to develop skills in value clarification.

The results of this study indicate that teachers in differing teaching fields do exhibit differences in values, although specific differences were not clearly identified by the study. Because of the potential influence of work values of teachers on the role models which they present and behaviors they exhibit in their interactions with students, it is recommended that future studies be conducted to provide work value profiles for various teaching fields. Because this is the first study of this type using secondary teachers as subjects, it would be beneficial to replicate this study in a variety of geographic and socioeconomic situations, in order to compare those results with the data obtained in this study. It must also be noted that participants in this study did so on a voluntary basis, and that those teachers who chose not to participate may hold somewhat different value profiles than the one described in this study. 


\section{A SELECTED BIBLIOGRAPHY}

Allport, G. W., Vernon, P. E. \& Lindzey, G. Study of Values. Boston: Houghton Mifflin, 1960 .

Beach, D. P. Necessary Work Values, Habits, and Attitudes: A Final Report. Jefferson City, Mo.: Missouri State Department of Education, Research Coordinating Unit, $1978 \mathrm{a}$.

Beach, D. P. Affective Work Competencies, Phase II, Final Report. Jefferson City, Mo.: Missouri State Department of Education, Research Coordination Unit, 1978b.

Best, J. W. Research in Education. Englewood Cliffs, N.J.: Prentice Hall, 1981 .

Bloom, B. S., Krathwohl, D. R., \& Masia, B. B. Taxonomy of Educational Objectives. Handbook II: Affective Domain. New York: David McKay Company, 1974.

Combs, A. W. \& Snygg, D. Individual Behavior. New York: Harper and Row, 1959.

Crites, J. O. Vocational Psychology. New York: McGrawHill, 1969 .

Curry, C. W. "Vocational Education and the Changing American Work Ethic." In Values, Concepts and Techniques, pp. 224-34. Washington, D.C.: National Education Association, 1976.

Dewey, J. Theory of Valuation. Chicago: The University Press, 1939 .

Drummond, R. J., Pinette, C. A. \& Smith, R. K. "Examining the Effects of Self-Concept and Work Values on Reading Achievement." Reading World, 1977, 16 (March): 206-212.

Elkind, D. A Sympathetic Understanding of the Child Six to Sixteen. Boston: Allyn and Bacon, Inc., 1971. 
Fenner, B. J. "The Development of the Ohio Work Values Inventory: An Investigation of Internal Characteristics." Ph.D. dissertation, Ohio University, 1972. Dissertation Abstracts International 1972 33/04A, p. 1433 (University Microfilms No. 72-26366).

Fenner, B. J. \& Hales, L. W. "Measuring the Work Values of Elementary School Children." Paper presented at the annual meeting of the American Educational Research Association, New Orleans, La., 1973a.

Fenner, B. J. \& Hales, L. W. "The Development of a Work Values Inventory." Paper presented at the annual meeting of the National Council on Measurement in Education, New Orleans, La., 1973b.

Freese, G. T. \& West, C. K. "Congruence, Empathy and Regard: A Comparison of Adolescent Ratings with Teacher Self-Ratings." Adolescence, 1972, 28 (Winter):525-29.

Gade, E. M. \& Peterson, G. "Intrinsic and Extrinsic Work Values and the Vocational Maturing of VocationalTechnical Students." Vocational Guidance Quarterly, 1977, 26 (December): 125-29.

Garrett, P. G. The Teachers We Need. Consumer and Homemaking Education, Opportunity and Challenge. Washington, D.C.: American Home Economics Association, 1971.

Ginzberg, E., Ginzberg, S. W., Axlerod, S. \& Heime, J. L. Occupational Choice: An Approach to a General Theory. New York: Columbia University Press, 1951.

Grace, J. C. "Work Values of Community College Students: An Exploratory Investigation of Freshmen at Middlesex Community College." Ph.D. dissertation, Boston College, 1972. Dissertation Abstracts International, $1974,38 / 05 \mathrm{~A}$, p. 2557 (University Microfilms No. $74-20703)$.

Gribbon, W. D. \& Lohnes, P. R. "Shifts in Adolescents" Vocational Values." Personnel and Guidance Journal, $1965, \underline{44}: 248-52$.

Hales, A. K. "A Comparative Study of the Work Values of Nurses versus the Work Values of Nurse Trainees." Master's thesis, Ohio University, 1977. 
Hales, L. W. "The Ohio Work Values Inventory: Development, Research and Utilization." Invited address presented at the annual meeting of the Research and Development Association for Education, Williamsburg, Va., November 1977.

Hales, L. W. \& Fenner, B. J. "Work Values of 5 th, 8 th and lith Grade Students." Vocational Guidance Quarterly, $1972 a, 20: 60-66$.

Hales, L. W. \& Fenner, B. J. "Sex and Social Class Differences in Work Values." Vocational Guidance Quarterly, $1972 \mathrm{~b}, 20: 199-203$.

Hales, L. W. \& Fenner, B. J. Ohio Work Values Inventory Manual. 1973a.

Hales, L. W. \& Fenner, B. J. "Sex and Social Class Differences in Work Values." Elementary School Guidance and Counseling, 1973b, 8,:26-32.

Hales, L. W. \& Hartman, T. P. "Personality, Sex and Work Values." Journal of Experimental Education, 1978, 47 (Fall): $16-21$.

Hales, L. W. \& Yackee, K. "Self-concepts, Sex and Work Values." Paper presented at the annual meeting of the American Educational Research Association, Chicago, Ill., 15-19 April 1974.

Hammond, M. "Motives Related to Vocational Choices of College Freshmen." Journal of Counseling Psychology, 1956, 19:257-61.

Handley, H. M. \& Shill, J. F. "Vocational Education Teachers' Evaluation of Preservice Professional Training as Related to Their Work Values and Attitudes toward Students and Teaching." Paper presented at the Mid-South Educational Research Association Conference, Memphis, Tenn., 14-17 November 1973.

Handley, H. M. \& Shill, J. F. Vocational Education Teachers Evaluation of Preservice Professional Training as Related to Their Work Values and Attitudes toward Students and Teaching. Mississippi State Department of Equcation, Jackson. Division of Vocational and Technical Education, June 1974 .

Harmin, M. \& Simon, S. B. "Values." In S. B. Simon \& H. Kirschenbaum (Eds.). Readings in Value Clarification. Minneapolis, MN: Winston Press, 1973. 
Hartman, T. P. "Differentiating among Vocational College Students with the VIP and OWVI." Ph.D. dissertation, Ohio University, 1977. Dissertation Abstracts International, 1977, 38/05A, p. 2557 (University Microfilms No. DBJ77-23465).

Holland, J. L. Making Vocational Choices: A Theory of Careers. Englewood Cliffs, N.J.: Prentice-Hall, Inc., I973.

Hopkins, K. D. \& Glass, G. V. Basic Statistics for the Behavioral Sciences. Englewood Cliffs, N.J.: PrenticeHall, Inc., 1978.

Horney, K. Our Inner Conflicts. New York: Norton, 1945.

Katz, M. Decisions and Values: A Rationale for Secondary School Guidance. New York: College Entrance Examination Board, 1963.

Kirschenbaum, H. \& Simon, S. B. "Values and the Futures Movement in Education." In Learning for Tomorrow. New York: Random House, $197 \overline{3}$.

Krause, D. A. "A Study of Work Values as They Relate to Holland's Six Personal Orientations." College of Education, Missouri University, 1970. (Unpublished.)

Maslow. A. H. Motivation and Personality. New York: Harper, 1954 .

Mitchell, M. M. "Teacher Attitudes." High School Journal, 1976, 59 (April):302-312.

Nie, N. H., Null, C. H., Jenkins, J. G., Steinbrenner, K. \& Bent, D. H. Statistical Package for the Social Sciences. New York: McGraw Hill Book Company, 1975.

Oliver, D. W. \& Shaver, J. P. Teaching Public Issues in the High School. Boston: Houghton Mifflin, 1966; reprint ed., Logan, Utah: Utah State University Press, 1974 .

Perrone, P. A. "Values and Occupational Preferences of Junior High School Girls." Personnel and Guidance Journal, 1965, 44:253-57.

Pullias, E. V. \& Young, J. D. A Teacher Is Many Things. Bloomington and London: Indiana University Press, 1968 . 
Purpel, D. \& Ryan, K. Moral Education .. . It Comes with the Territory. Berkeley, Cal.: McGutchan Publishing Corp., 1976.

Queensland Board of Teacher Education. Secondary Schools and the World of Work: The Experience of Queensland Teachers. Toowong, Australia: Queensland Board of Teacher Education, July 1981.

Raths, L., Harmin, M. \& Simon, S. Values and Teaching. Columbus, Ohio: Charles E. Merrill Publishing Co., 1978.

Roe, A. "Early Determinants of Vocational Choice." Journal of Counseling Psychology, 1957, 4:212-217.

Rogers, C. R. "Toward a Modern Approach to Values: The Valuing Process in the Mature Person." In S. B. Simon \& H. Kirschenbaum (Eds.). Readings in Value Clarification. Minneapolis, MN: Winston Press, 1973.

Rokeach, M. The Nature of Human Values. New York: Free Press, 1973.

Rosenberg, M. Occupations and Values. Glencoe, I11.: Free Press, $19 \overline{57 .}$

Sarason, I. G. \& Sarason, B. R. Modeling and Role-Playing in the Schools: A Manual with Special Reference to the Disadvantaged Student. Washington, D.C.: Office of Education, 1973.

Scott, W. E., Jr. \& Day, G. L. "Personality Dimensions and Vocational Interests among Graduate Business Students." Journal of Counseling Psychology, 1972, 19: $30-36$.

Senesh, L. "The Challenge of Value Commitment." In Values, Concepts and Techniques, pp. 277-87. Washington, D.C.: National Education Association, 1976.

Shaver, J. P. \& Berlack, K., eds. Democracy, Pluralism, and the Social studies: Readings and Commentary. Boston: Houghton Mifflin, 1968.

Shaver, J. P. \& Larkins, A. G. "The Analysis of Public Issues: Concepts, Materials, Research." Report to the U.S. Office of Education, Project No. 6-2288. Logan, Utah: Bureau of Educational Research, 1969. 
Shaver, J. P. \& Strong, W. Facing Value Decisions: Rationale-Building for Teachers. Belmont, Cal.: Wadsworth Publishing Co., Inc., 1976.

Simon, S. B. \& de Sherbinin, P. "Values Clarification: It Can Start Gently and Grow Deep." Phi Delta Kappan, 1975,56 (June) : 679-683.

Slocum, W. W., Jr. \& Hand, H. H. "Prediction of Job Success and Employee Satisfaction for Executives and Foremen." Training \& Development Journa1, 1971, 25 (October): 28-37.

Stefflre, B. Tentative Manual for Vocational Values Inventory. East Lansing: Michigan State University, 1962.

Smith, G. D. Attitudes of Teachers toward Career Education. Greeneville, Tenn.: Greeneville City Schools, Bureau of Elementary and Secondary Education, October 1974.

Super, D. E. Work Values Inventory. Boston: Houghton Mifflin, 1968 .

Super, D. E. Manual for the Work Values Inventory. Boston: Houghton MiffIin, 1970.

Thomas, H. B. "The Effects of Social Position, Race, and Sex on Work Values of Ninth Grade Students." Paper presented at the annual meeting of the American Research Association, New Orleans, La., 25 February--1 March 1973.

Tyson, J. C. \& Carroll, M. A. Conceptual Tools for Teaching in Secondary Schools. Boston: Houghton Miffin Co., 1970 .

Vanderink, P. "Identification and Comparison of Work Values and Job Perceptions of Urban Business Education Students and Clerical Office Workers." Delta Pi Epsilon Journal, 1980, 22 (October):21-34. 


\title{
APPENDIX A
}

\section{OHIO WORK VALUES INVENTORY}

Information regarding the Ohio work Values Inventory is available through:

\author{
Publication Test Service \\ McGraw Hill Publishing Company \\ DelMonte Research Park \\ Monterey, California 93940
}




\section{APPENDIX B}

\section{BIOGRAPHICAL DATA SHEET}

1. Sex: Male Female

2. Age :

3. Years of Teaching Experience:

4. School Location:

Urban

Rural

5. School Name:

6. Please check the ONE area that most closely identifies your teaching assignment.

Agriculture

Art

Business/Careers/Personal Finance

English/Language Arts

Foreign Language

History/Social Studies

Home Economics

Industrial Arts/Shop

Mathematics/Computer Science

Music

Physical Education/Health

- Science--Biological

- Science--Physical

- Science--General

_ Special Education

_ Speech/Drama

Other: Please specify 
APPENDIX C

COVER LETTER TO PARTICIPANTS

THE WORK VALUES OF SECONDARY TEACHERS:

A COMPARATIVE STUDY BY TEACHING ASSIGNMENT

Introduction

There is a growing emphasis on the need for introducing the world of work and for laying a foundation in career decision making at all levels of the school system. School professionals are increasingly being asked to take part in helping young people become more aware of their value orientations, the process by which values are shaped, and the integration of these into their consideration of work plans.

The influence teachers have on their students has been documented in several areas. The values regarding work that classroom teachers hold will affect their approach to teaching; and in turn will provide role modeling to the students.

Purpose of the Study

The purpose of this study is to determine the general work values held by classroom teachers. The results will be divided by subject area to determine differences which may exist among teachers in a variety of teaching assignments.

The information gained in this type of study can be used in many ways, some of which are listed below:

1. Planning and evaluating curriculum.

2. Helping teachers understand areas of common agreement or the differences among peers in the same or other disciplines.

3. Helping administrators understand and work more effectively with their staff. 
4. When teachers are aware of their own personal work values, they are less likely to impose them on their students.

\section{Study Participants}

All teachers providing data for this study participate on a voluntary basis. All results will be strictly anonymous and will be safeguarded on a professional level.

I wish to thank all participants for their time and input on this project, your cooperation is greatly appreciated.

Charlotte M. Klampe

Graduate Studies--Education

Portland State University 


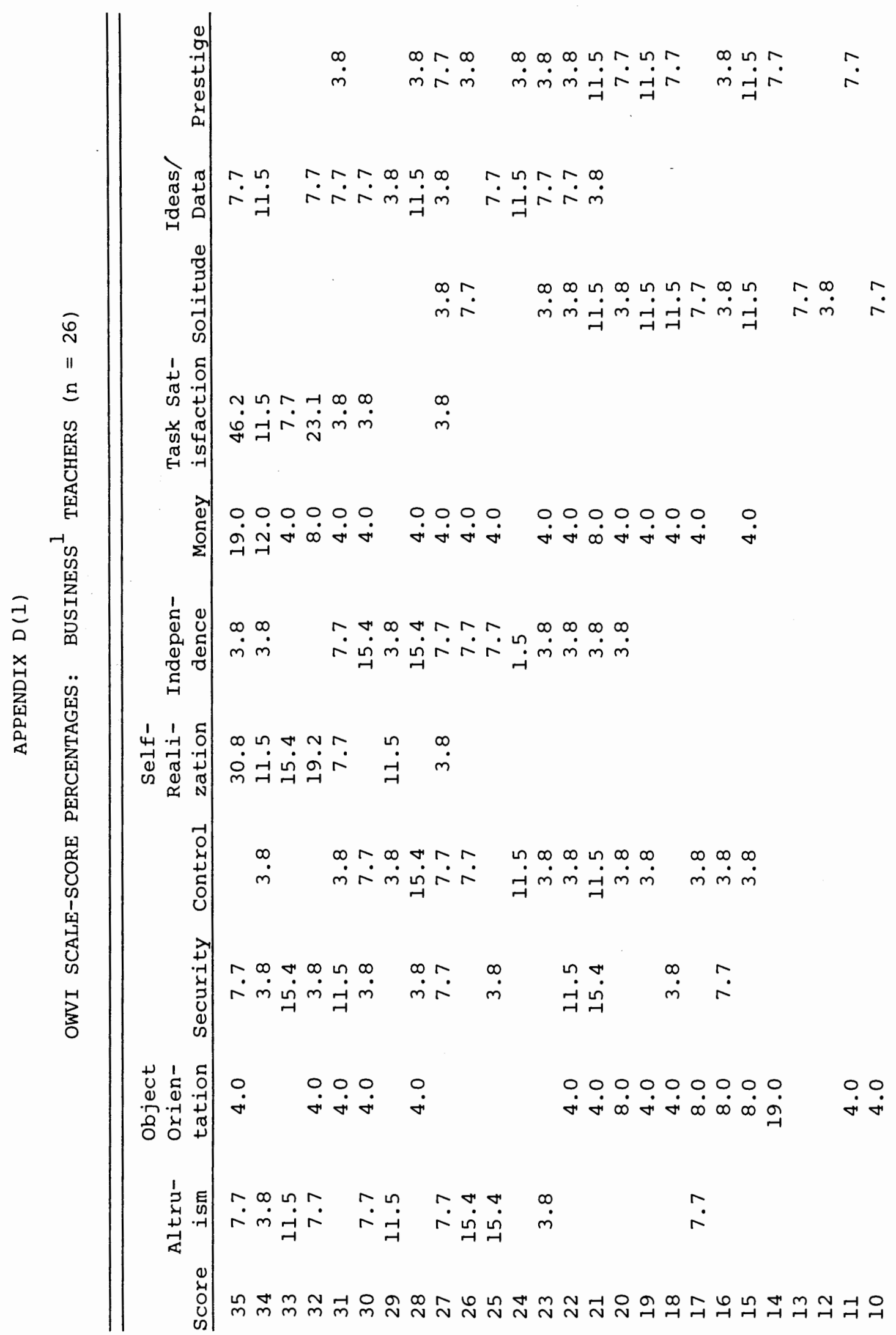




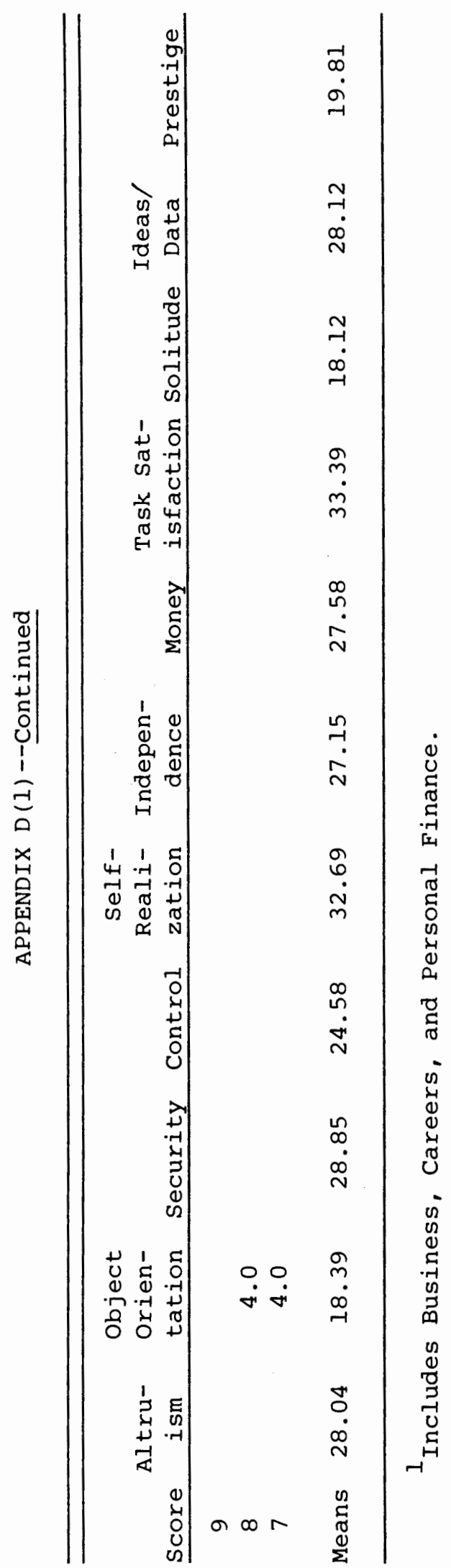




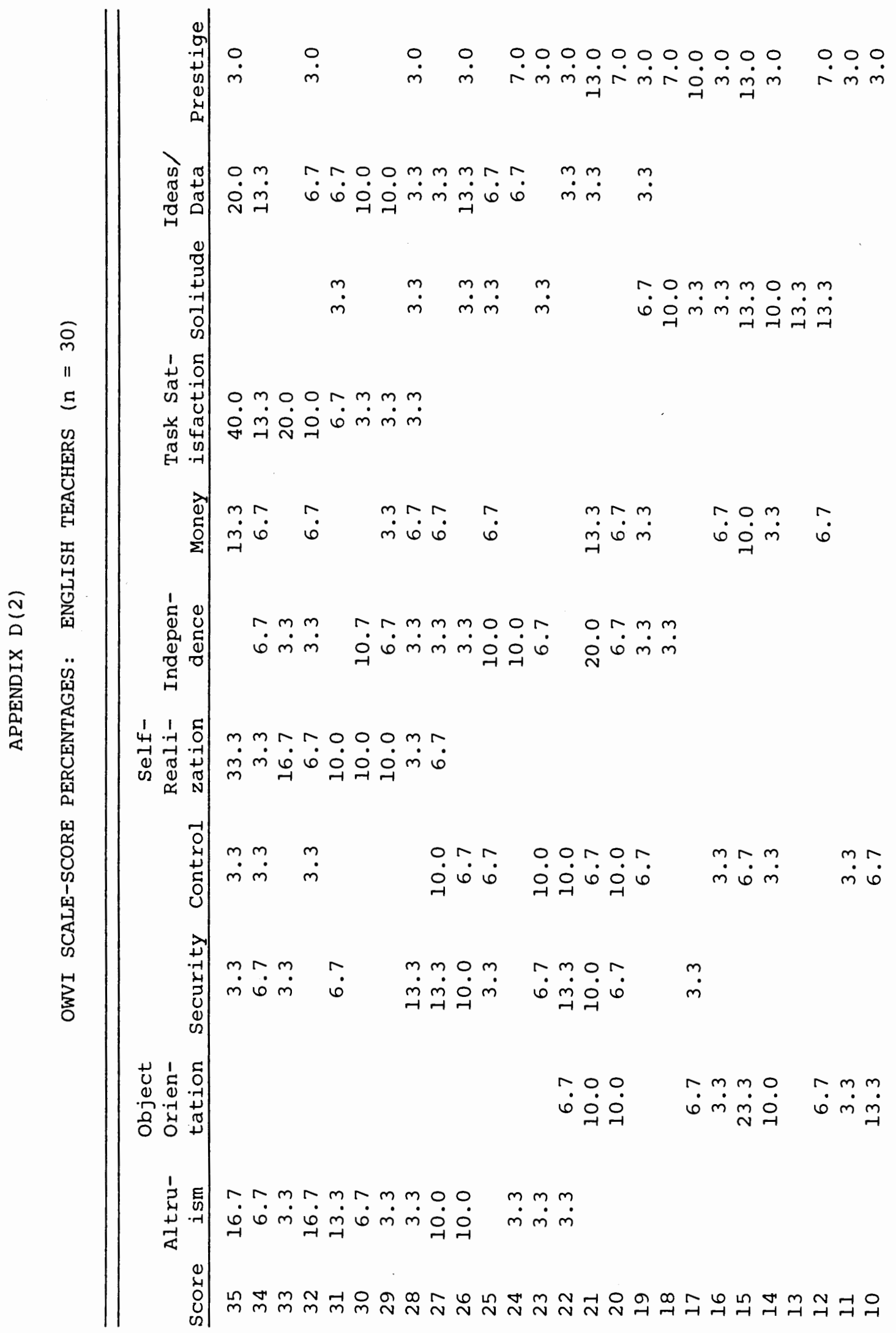




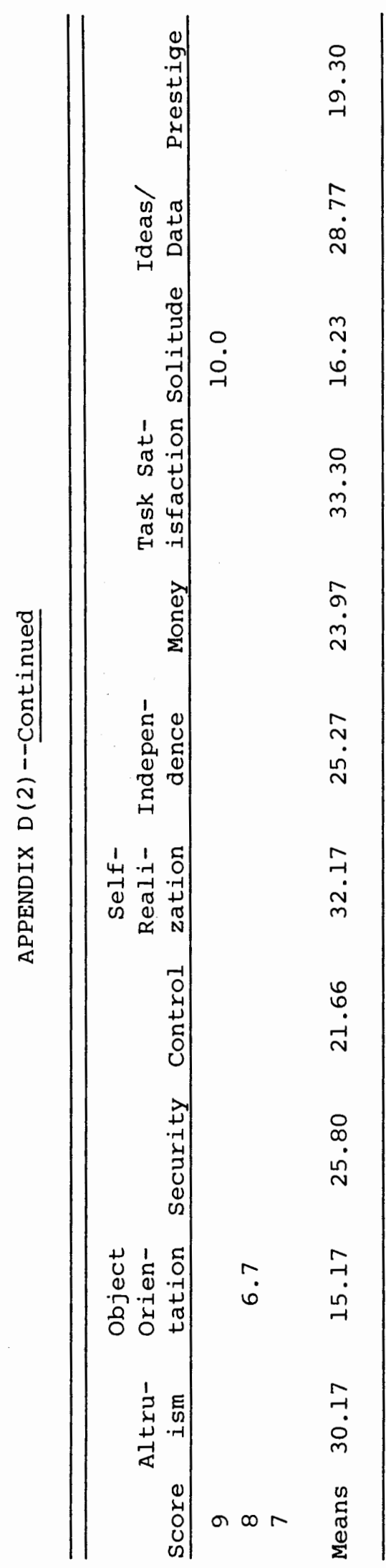




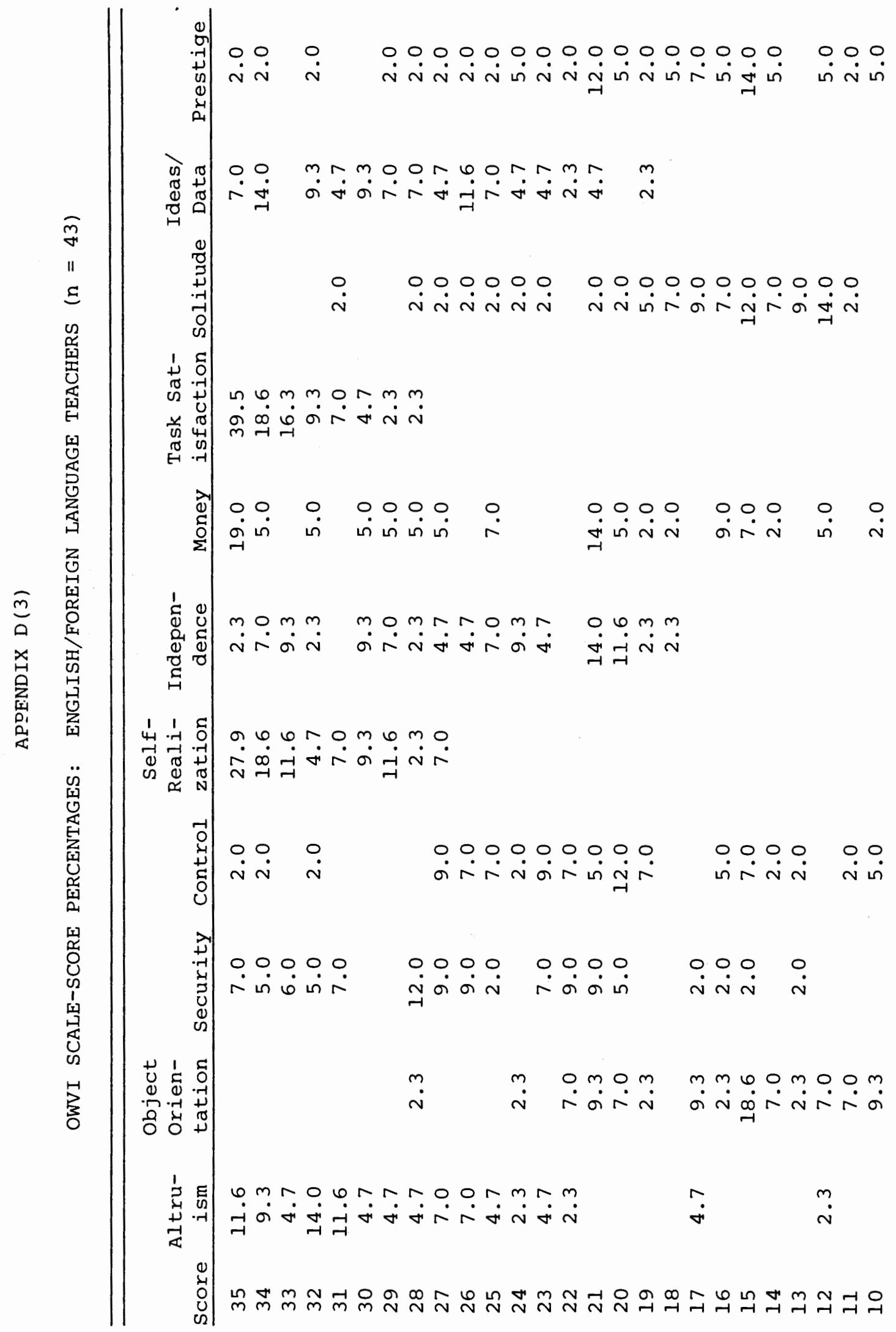




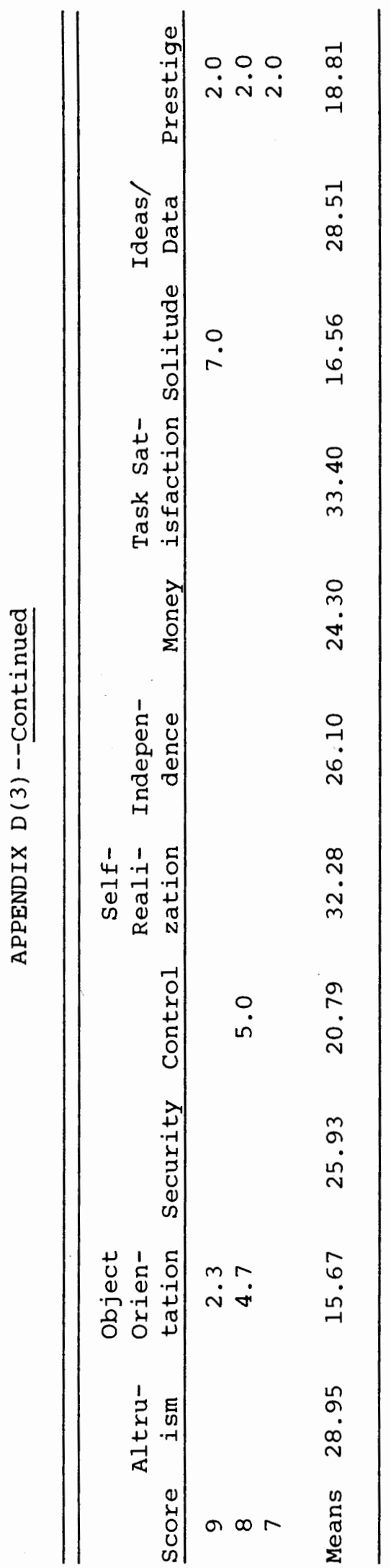




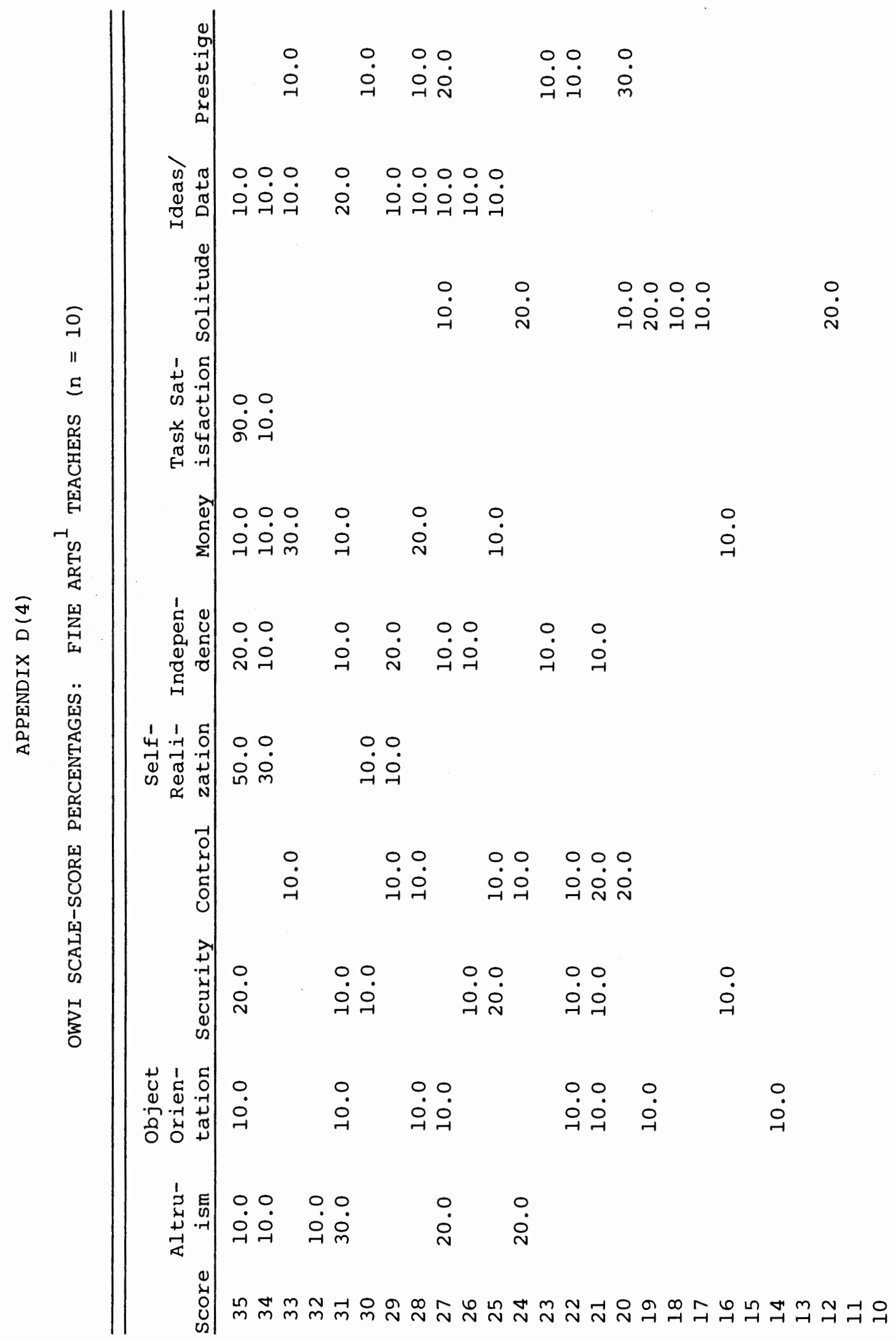




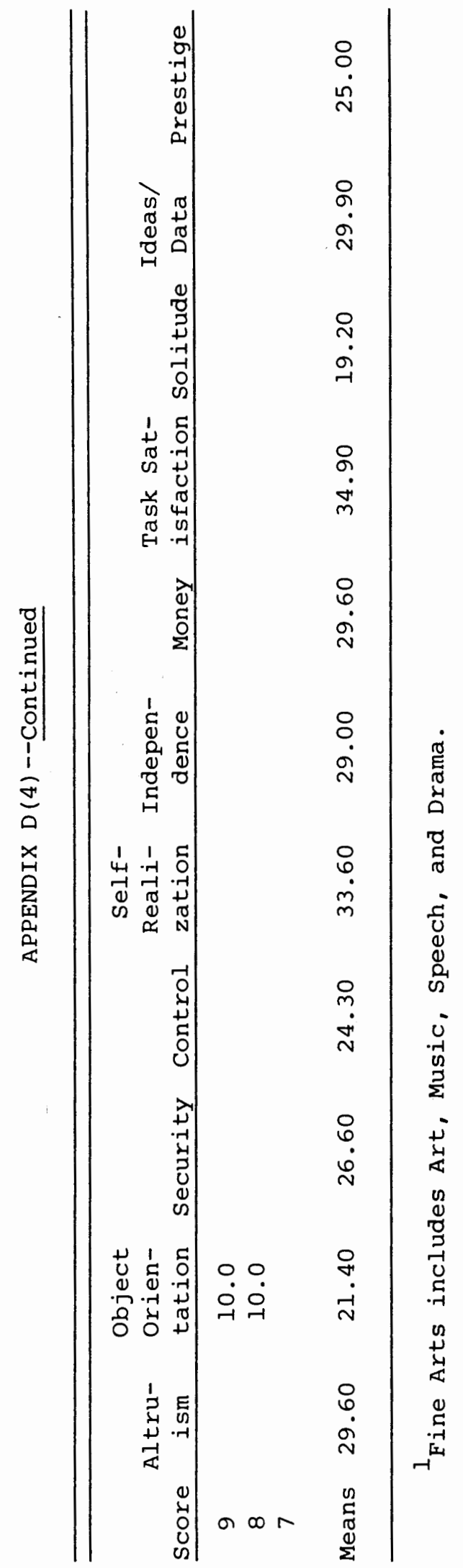




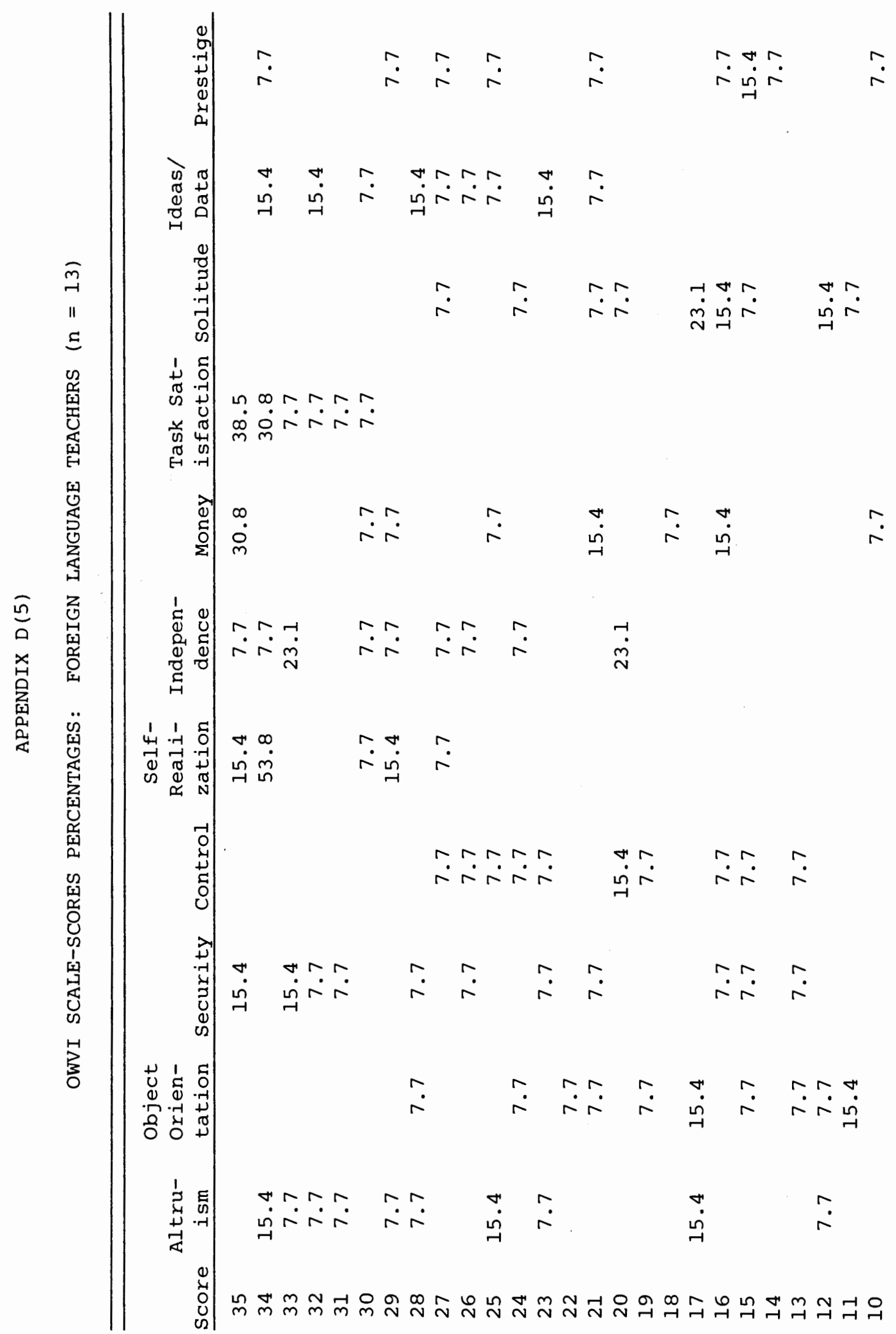




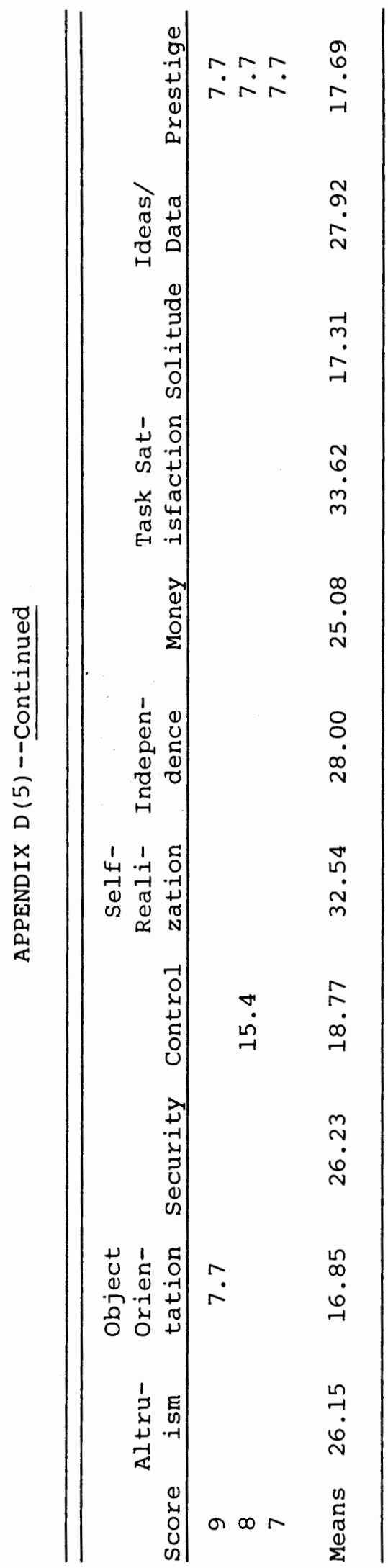




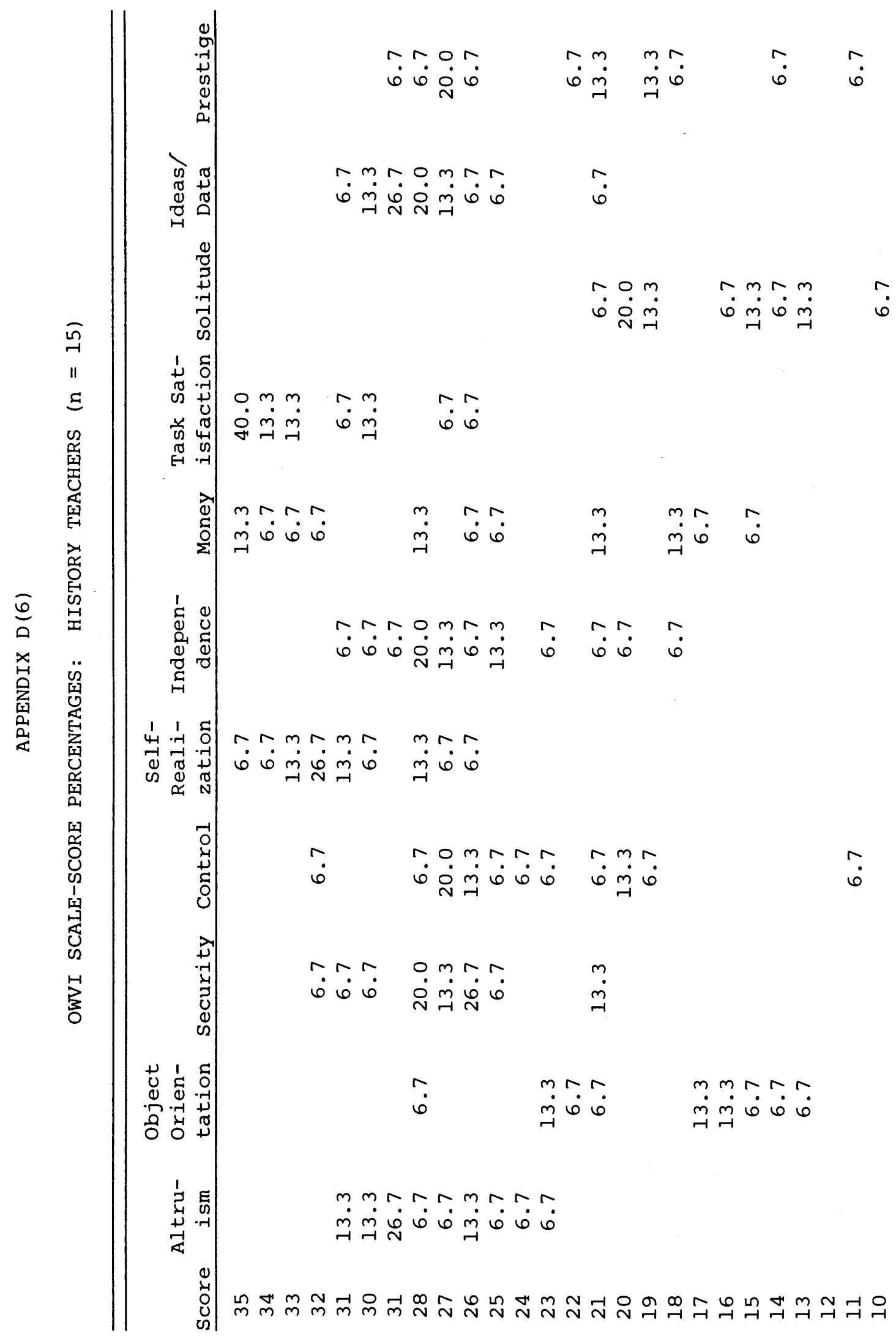




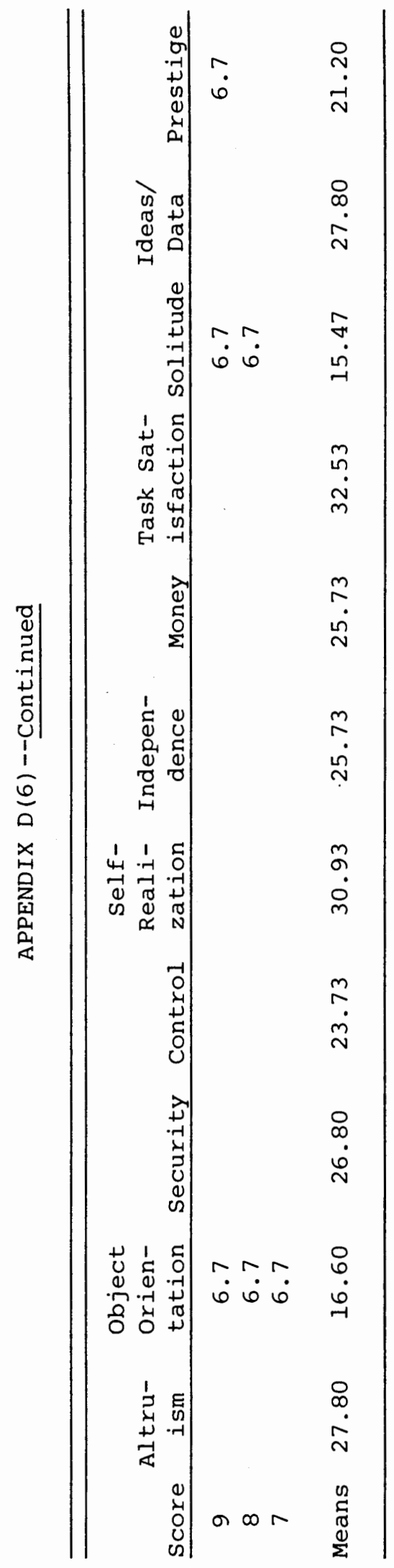




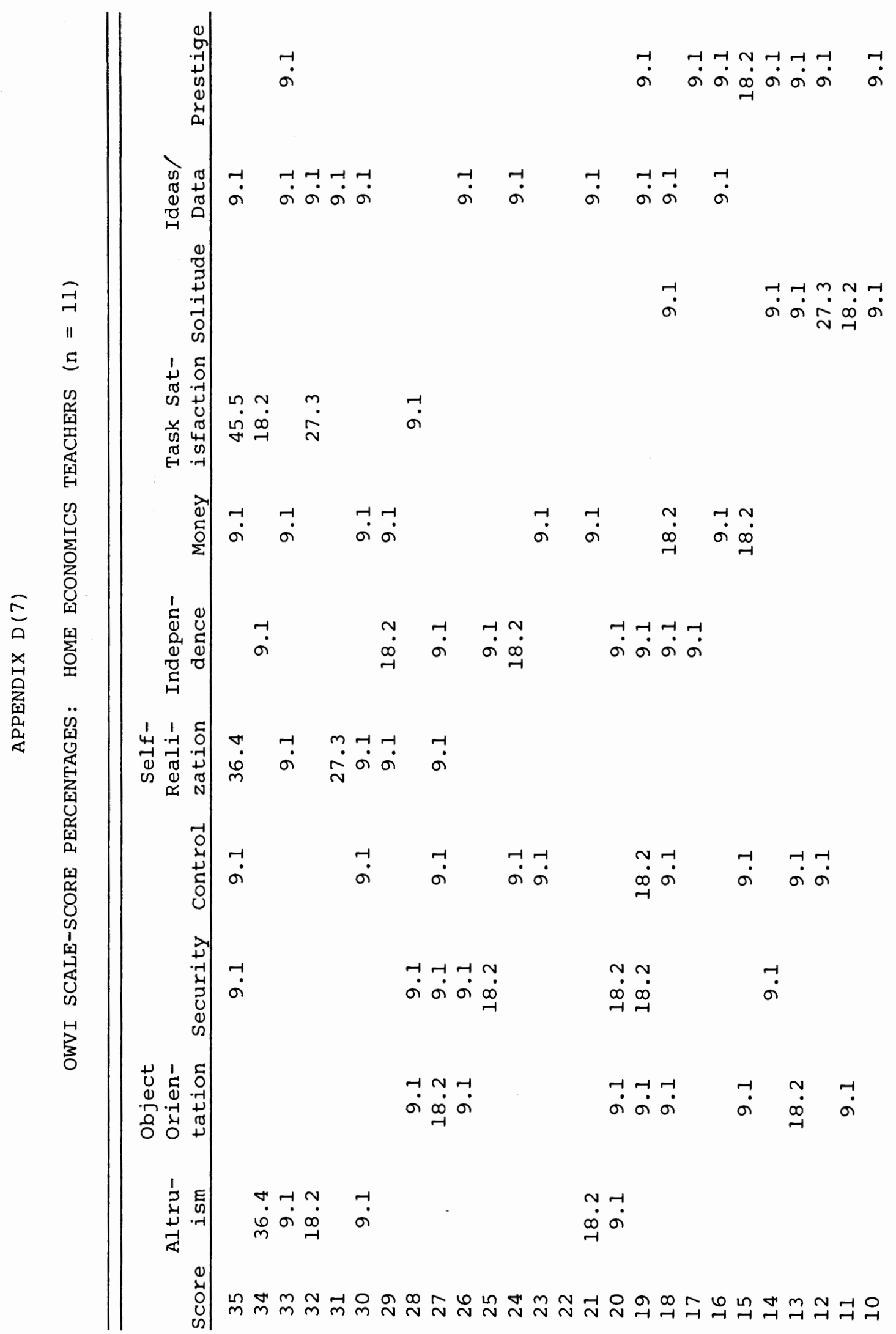




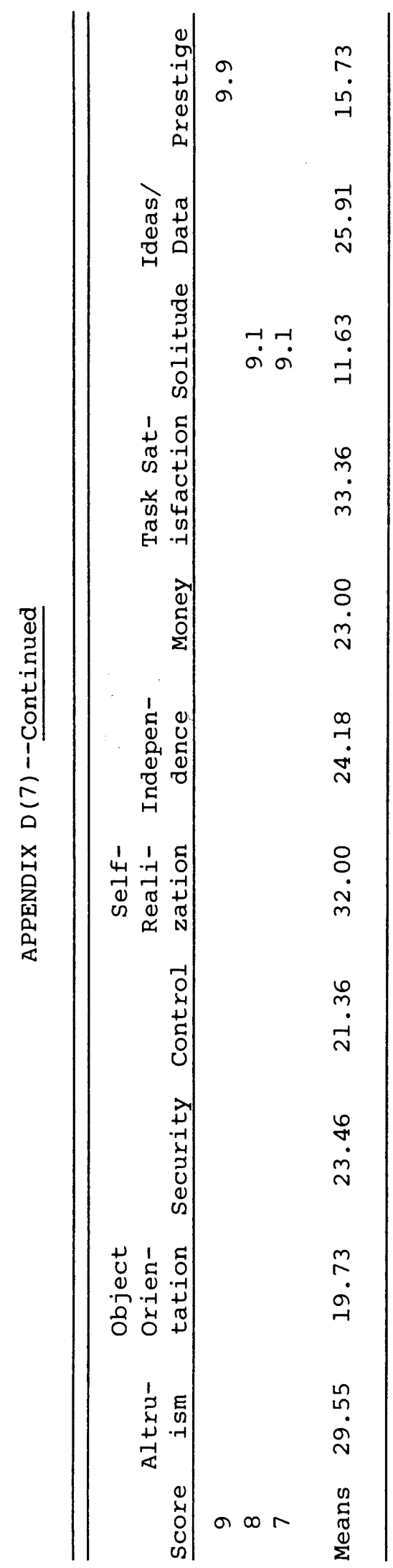




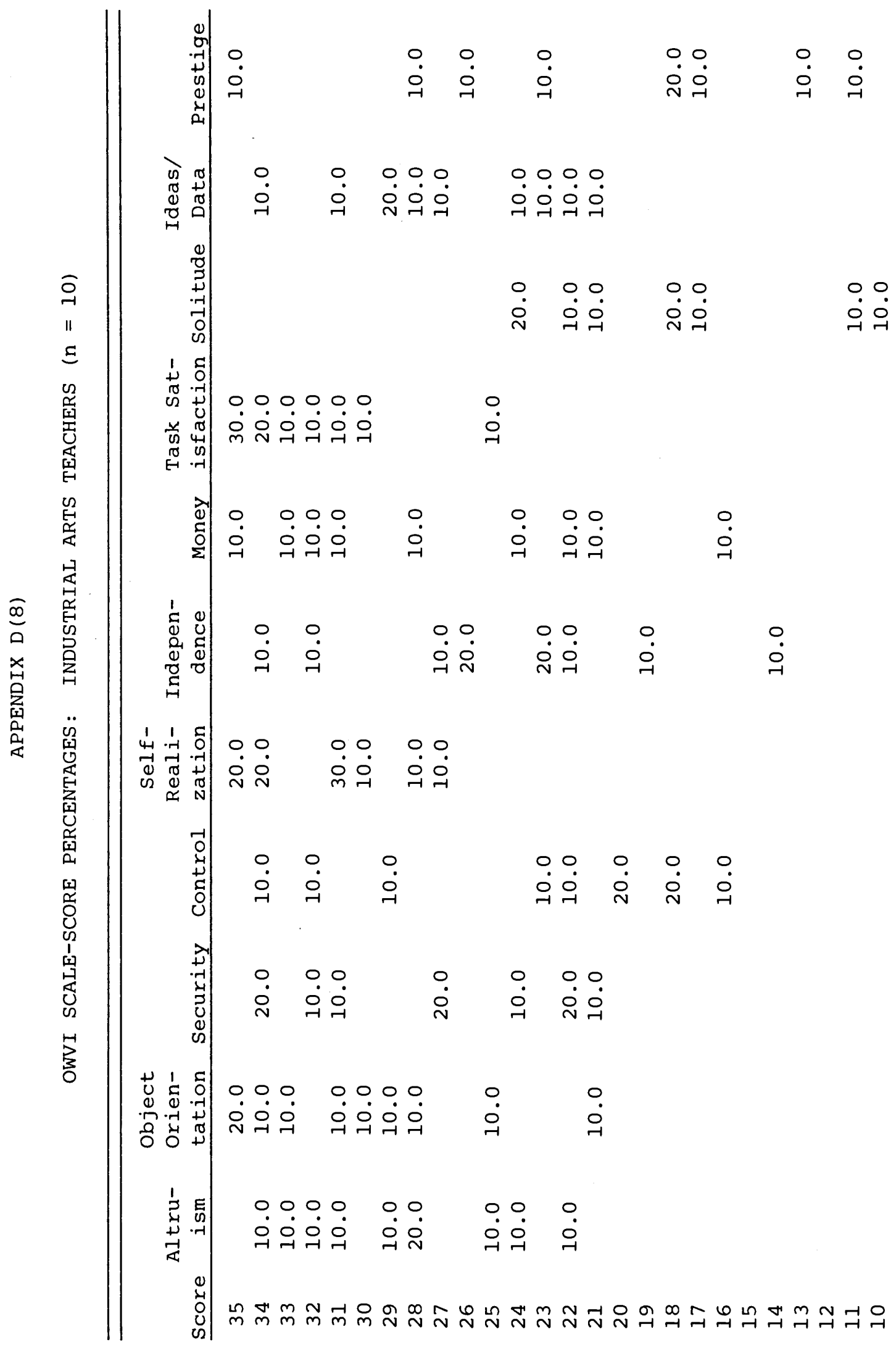




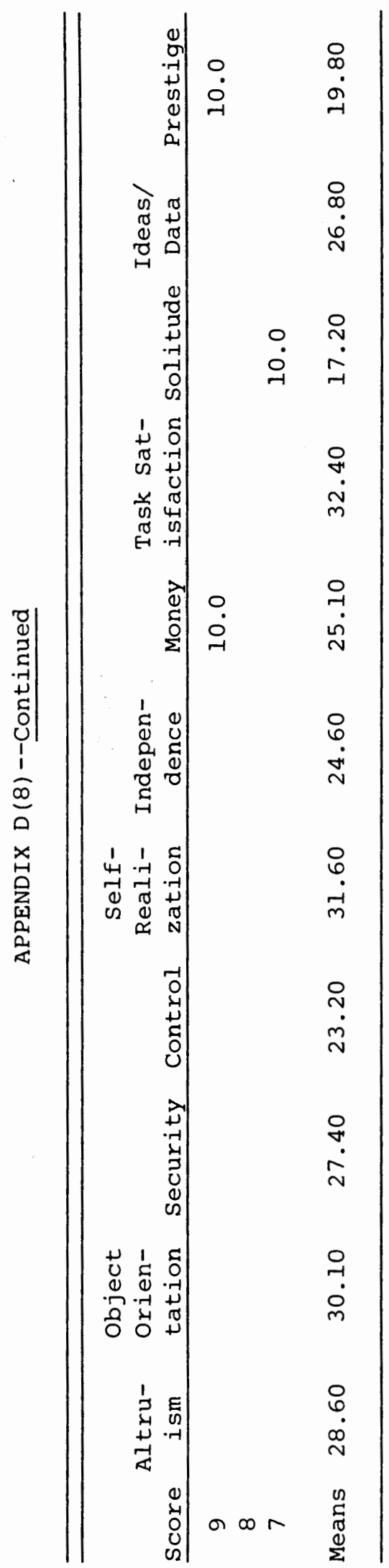




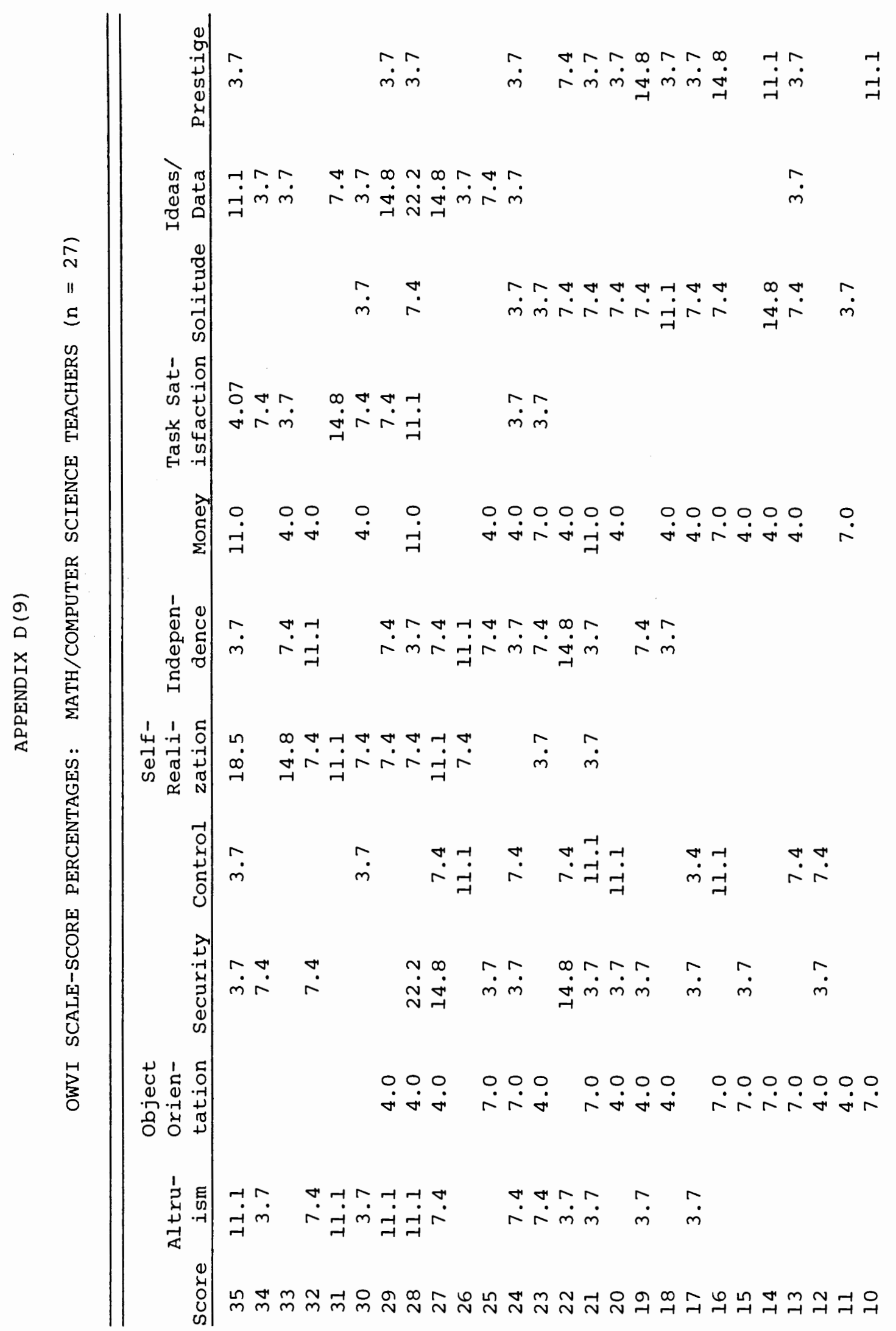




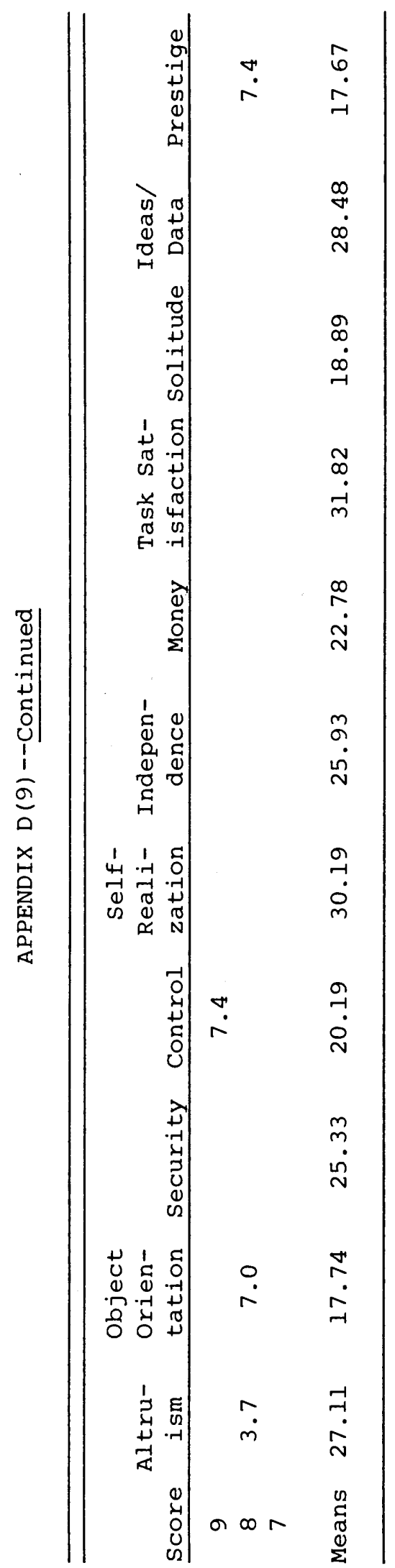




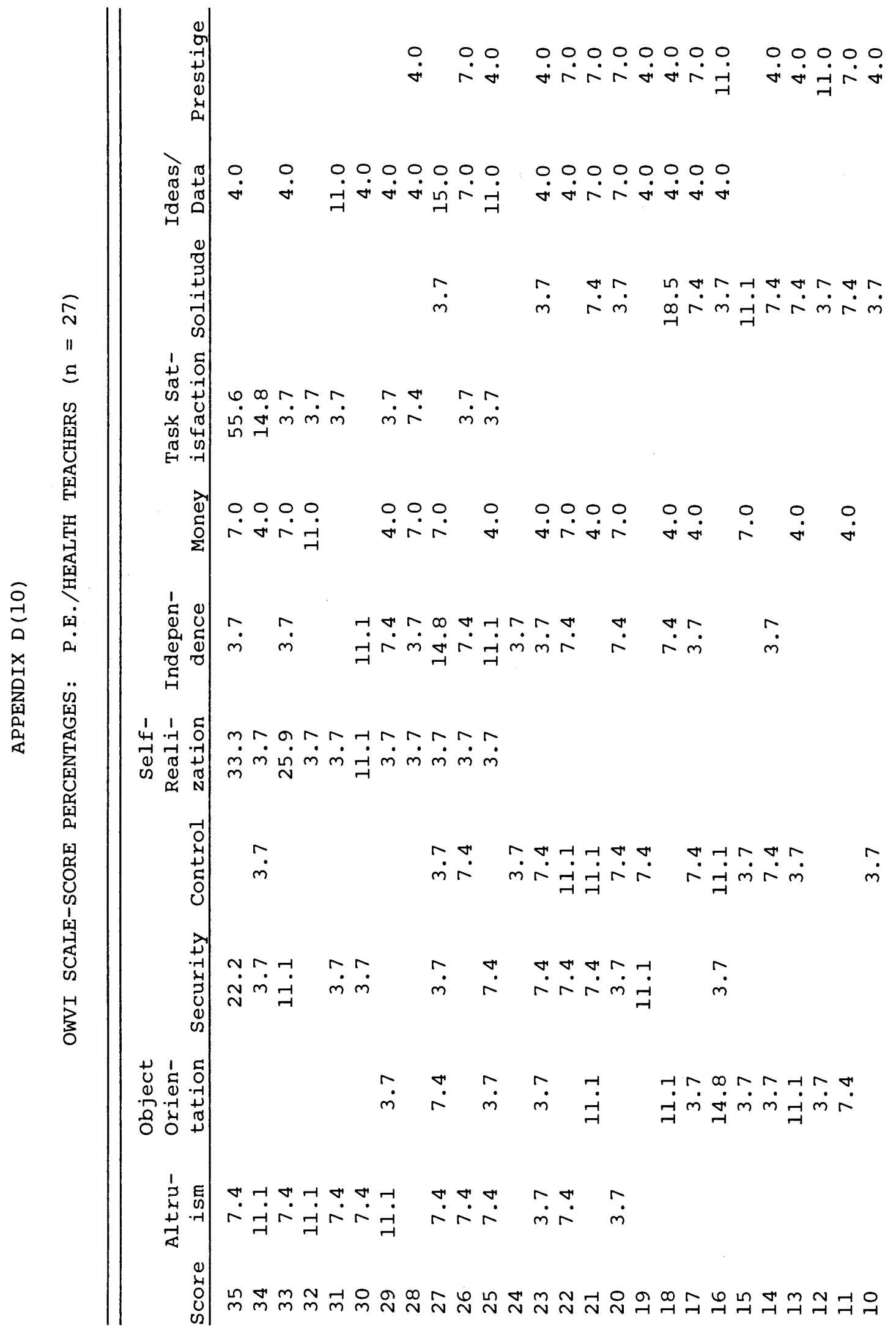




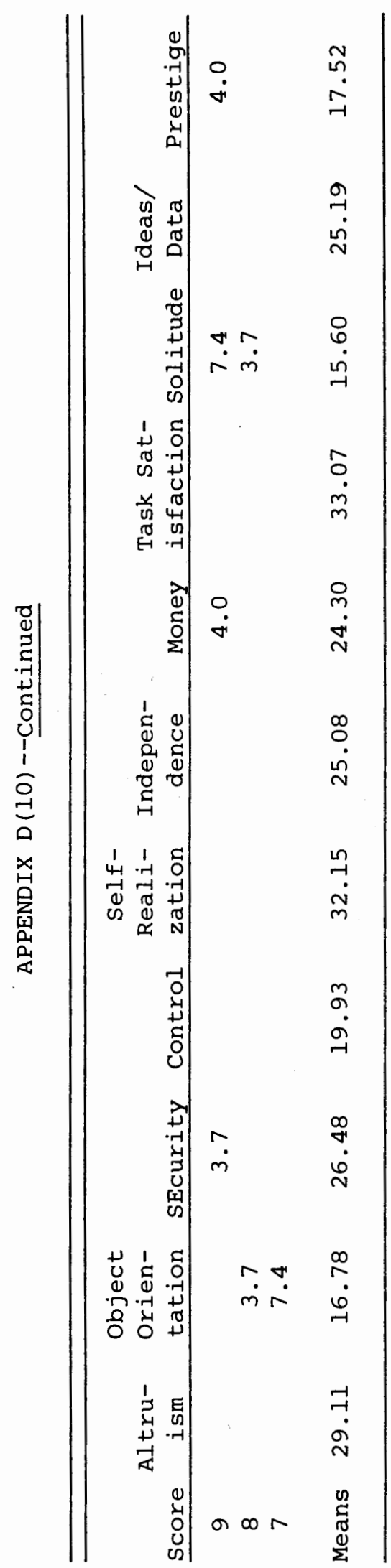




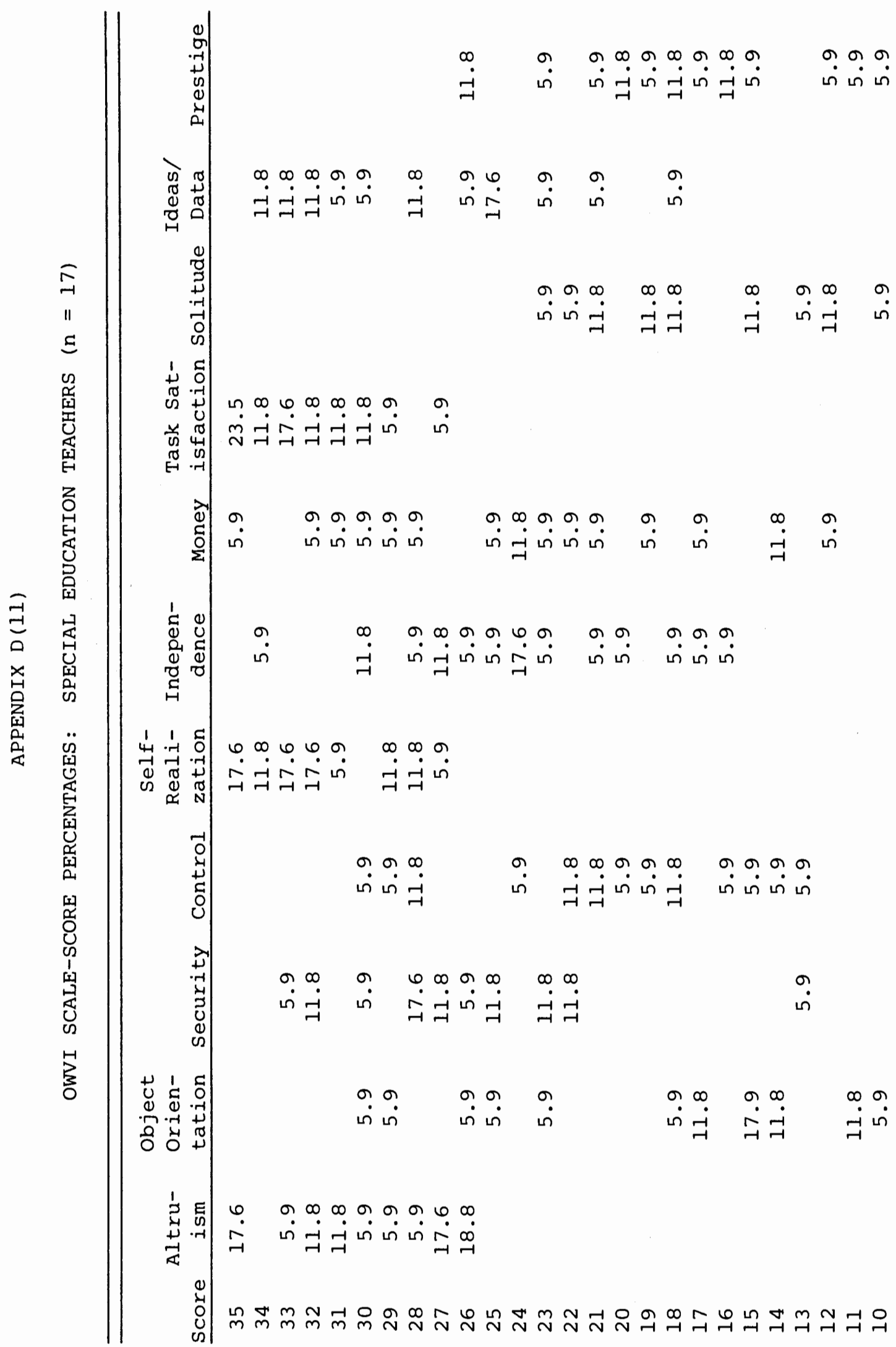




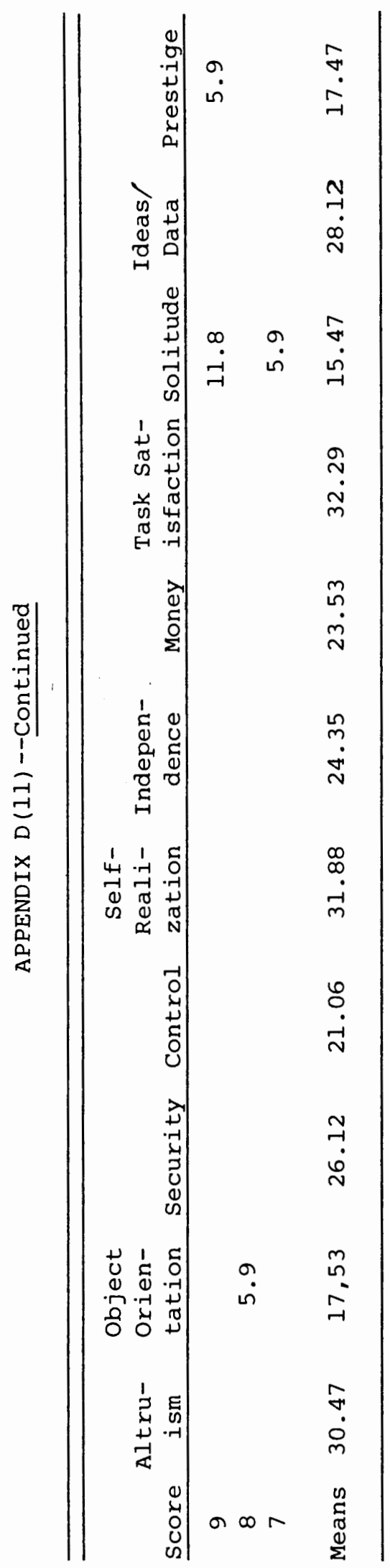




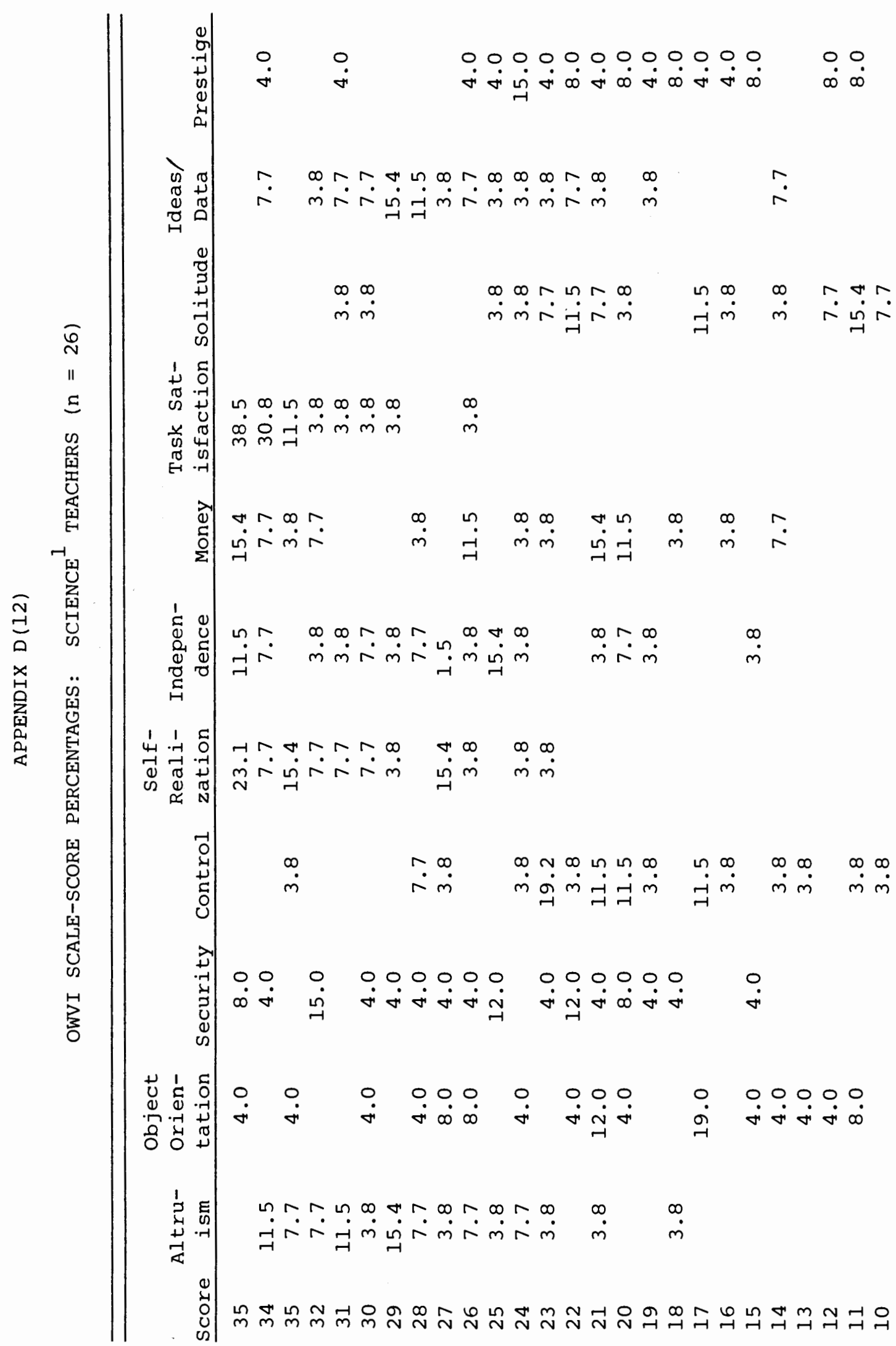




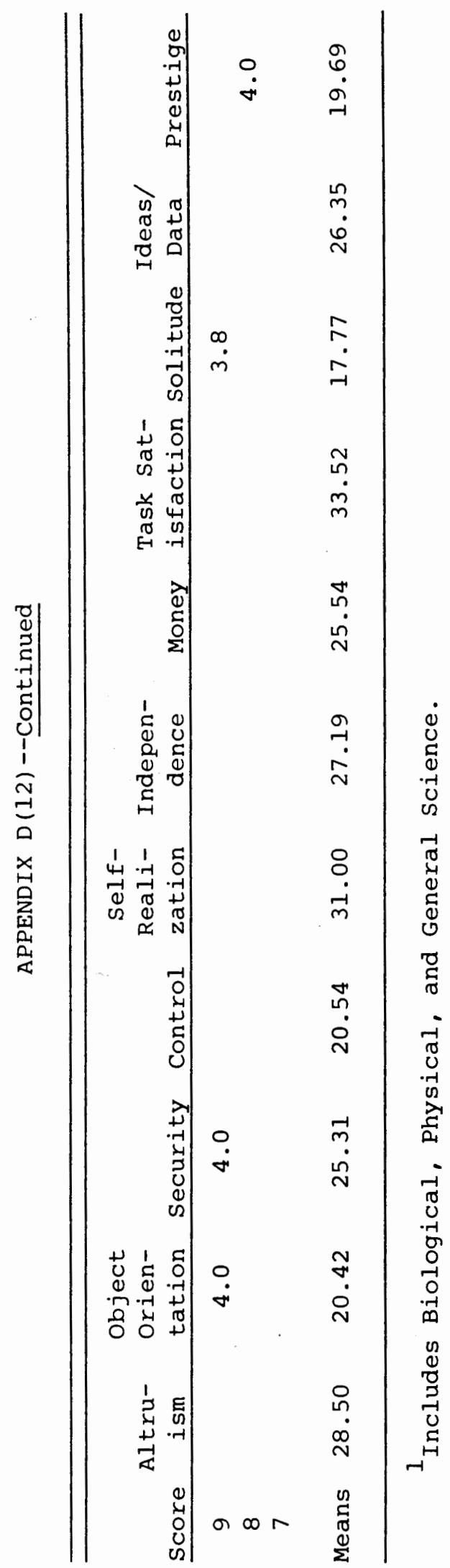




\section{APPENDIX E}

\section{SCHOOLS PARTICIPATING IN THE STUDY}

The majority of the schools contacted for participation in this study were from a list provided the researcher by the Marion County Education Service District. The largest schools within the county and those in closest proximity to the researcher were selected. Those schools marked with an $(*)$ indicate that participants were contacted through classes at Portland State University.

*1. Beaverton Junior High School Beaverton, Oregon

*2. Centennial High School

Portland, Oregon

3. Gervais Union High School Gervais, Oregon

4. McKay High School Salem, Oregon

5. McNary High School

Salem, Oregon

6. North Marion High School Woodburn, Oregon

7. North Salem High School

Salem, Oregon

*8. Silverton Union High School

Silverton, Oregon

9. South Salem High School 
10. Sprague High School

Salem, Oregon

11. Tigard Junior High Schools Tigard, Oregon

12. Woodburn High School

Woodburn, Oregon

*School Not Listed 